\title{
An "island" in the stratosphere - on the enhanced annual variation of water vapour in the middle and upper stratosphere in the southern tropics and subtropics
}

\author{
Stefan Lossow ${ }^{1}$, Hella Garny ${ }^{2}$, and Patrick Jöckel ${ }^{2}$ \\ ${ }^{1}$ Karlsruhe Institute of Technology, Institute for Meteorology and Climate Research, Hermann-von-Helmholtz-Platz 1, \\ 76344 Leopoldshafen, Germany \\ ${ }^{2}$ Deutsches Zentrum für Luft- und Raumfahrt (DLR), Institut für Physik der Atmosphäre, 82234 Oberpfaffenhofen-Wessling, \\ Germany
}

Correspondence to: Stefan Lossow (stefan.lossow@kit.edu)

Received: 29 April 2017 - Discussion started: 8 May 2017

Revised: 15 August 2017 - Accepted: 29 August 2017 - Published: 27 September 2017

\begin{abstract}
The amplitude of the annual variation in water vapour exhibits a distinct isolated maximum in the middle and upper stratosphere in the southern tropics and subtropics, peaking typically around $15^{\circ} \mathrm{S}$ in latitude and close to $3 \mathrm{hPa}(\sim 40.5 \mathrm{~km})$ in altitude. This enhanced annual variation is primarily related to the Brewer-Dobson circulation and hence also visible in other trace gases. So far this feature has not gained much attention in the literature and the present work aims to add more prominence. Using Envisat/MIPAS (Environmental Satellite/Michelson Interferometer for Passive Atmospheric Sounding) observations and ECHAM/MESSy (European Centre for Medium-Range Weather Forecasts Hamburg/Modular Earth Submodel System) Atmospheric Chemistry (EMAC) simulations we provide a dedicated illustration and a full account of the reasons for this enhanced annual variation.
\end{abstract}

\section{Introduction}

Water vapour is one of the most important trace constituents in the stratosphere. It owes this importance to its role as a greenhouse gas, its impact on the stratospheric ozone budget and its usefulness as a tracer of dynamical processes. As the most important greenhouse gas in the lower stratosphere, water vapour plays a decisive role in global warming at the Earth's surface (Riese et al., 2012). In this context, water vapour is part of an important feedback mecha- nism. A warmer surface climate leads to an increase in stratospheric water vapour, which causes the surface temperatures to increase further. Dessler et al. (2013) estimated this water vapour feedback to be about $0.3 \mathrm{~W} \mathrm{~m}^{-2}$ for a $1 \mathrm{~K}$ temperature anomaly in the middle troposphere. For the ozone budget, water vapour is important in different ways. On one hand, it is an essential component of polar stratospheric clouds (PSCs). The heterogenous chemistry taking place on the cloud particle surfaces is responsible for the severe ozone depletion in the polar lower stratosphere during winter and spring, in particular in the Antarctic. On the other hand, water vapour is also the primary source of hydrogen radicals $\left(\mathrm{HO}_{x}\right.$ $=\mathrm{OH}, \mathrm{H}, \mathrm{HO}_{2}$ ) in the stratosphere. These radicals destroy ozone within autocatalytic cycles and are especially important in the lower- and the uppermost part of the stratosphere (Brasseur and Solomon, 2005). Since the chemical lifetime of water vapour is of a similar order to the typical timescales of dynamical processes, it can be used to diagnose such processes. In the stratosphere this concerns of course primarily the Brewer-Dobson circulation as highlighted by the tape recorder in the tropical lower stratosphere (Mote et al., 1996).

The water vapour budget in the stratosphere is determined by a number of processes. The input from the troposphere and the in situ oxidation of methane and molecular hydrogen are the major sources of stratospheric water vapour. The reaction of water vapour with $\mathrm{O}\left({ }^{1} \mathrm{D}\right)$ and photodissociation are the most important sink processes. In general the water vapour volume mixing ratio increases with altitude in the 
stratosphere, primarily due to the dominant role of methane oxidation (Le Texier et al., 1988). The efficiency of this processes increases with altitude and typically maximises in the upper stratosphere. Around the stratopause the water vapour volume mixing ratio generally exhibits a pronounced maximum in the vertical distribution. Above, photodissociation dominates the water vapour budget.

Due to the importance of water vapour in the stratosphere, the research has a large focus on understanding its long-term evolution and the drivers behind it. This concerns changes in the input from the troposphere, abundances of methane and dynamical processes, as well as the influence of the Sun or volcanic eruptions (e.g. Oltmans et al., 2000; Rosenlof et al., 2001; Randel et al., 2006; Hurst et al., 2011; Hegglin et al., 2014; Dessler et al., 2014, 2016; Urban et al., 2014; Eichinger et al., 2015; Schieferdecker et al., 2015; Tao et al., 2015; Brinkop et al., 2016; Löffler et al., 2016). In the present work we focus on variability on a much shorter timescale, namely the annual variation. In the middle and upper stratosphere in the southern tropics and subtropics a pronounced and isolated maximum in the amplitude of the annual variation can be observed (which we simply refer to as enhanced annual variation). This region is normally associated with the semi-annual variation, which prominently maximises in the tropical upper stratosphere (Carr et al., 1995; Jackson et al., 1998). The enhanced annual variation as such has been observed in the past and some references exist in the literature. Most prominently Jackson et al. (1998) showed this in observations from the HALOE (Halogen Occultation Experiment) instrument aboard UARS (Upper Atmosphere Research Satellite). Other instances can be found, for example, in the work of Holton and Choi (1988) or Randel et al. (1998), which show this feature in methane. Since $\mathrm{H}_{2} \mathrm{O}+2 \cdot \mathrm{CH}_{4}$ is approximately a conserved parameter in the stratosphere and lower mesosphere (Le Texier et al., 1988; Siskind and Summers, 1998) the structure and variability of methane and water vapour are tightly linked with each other. All these publications have, however, a much wider scientific focus: variability in general and atmospheric transport. This motivated us to specifically highlight the enhanced annual variation in the southern tropics and subtropics. On one hand, we aim to provide a dedicated description of this feature. On the other hand, we aim to provide a full attribution of the reasons for this feature, which has been associated with the Brewer-Dobson circulation (Jackson et al., 1998). To do so we utilise both satellite observations and model simulations. The former we use primarily for the description and characterisation, while the latter are employed for the explanation and attribution of the feature. The observational results are mostly based on Envisat/MIPAS nominal mode measurements (Fischer et al., 2008). Those were performed almost daily, typically covering the altitude range from the upper troposphere to the lower mesosphere. We focus on the time period from January 2005 to the end of the MIPAS mission in April 2012 during which the observations were based on the same spectral resolution (Fischer et al., 2008). The data were retrieved with the IMK/IAA processor, which is a collaboration between the Institut für Meteorologie und Klimaforschung (IMK) in Karlsruhe, Germany and the Instituto de Astrofísica de Andalucía (IAA) in Granada, Spain (von Clarmann et al., 2009). The model results employed in this work are based on simulations with the EMAC model (Jöckel et al., 2016). These are based on the REF-C1SD (transient hindcast reference simulation with specified dynamics) scenario as defined by the SPARC (Stratospheretroposphere Processes And their Role in Climate) ChemistryClimate Model Initiative (Eyring et al., 2013). The specified dynamics data are taken from the Interim ECMWF (European Centre for Medium-Range Weather Forecasts) Reanalysis project (ERA-Interim, Dee et al., 2011). However, water vapour itself is not nudged (Jöckel et al., 2016). The simulations we employ here cover the time period from 2008 to 2012. They are equivalent to those labelled "RC1SD" in the work of Brinkop et al. (2016) with two exceptions. On one hand, the use of specified dynamics is extended up to $1 \mathrm{hPa}$ (instead of $10 \mathrm{hPa}$ ). On the other hand, the simulations here contain additional diagnostic tracers for the chemical production and loss of water vapour (ProdH2O and LossH2O). These tracers are accumulated in every chemical reaction if water vapour is produced or destroyed. Analogous tracers for ozone are documented by Jöckel et al. (2016). All observational and model results and analyses in this work are based on monthly and zonal mean data.

In the next section we describe and characterise the enhanced annual variation in the middle and upper stratosphere in the southern tropics and subtropics based on the satellite observations. A detailed discussion of the reasons for this feature is subsequently provided in Sect. 3 .

\section{Description}

Figure 1 shows the amplitude (left panel) and the phase (right panel) of the annual variation in water vapour as function of latitude and pressure derived from the MIPAS IMK/IAA v220/221 data set (Schieferdecker et al., 2015). The right axes of the panels indicate the log-pressure height using an atmospheric scale height of $7 \mathrm{~km}$. All geometric altitudes noted in this paper are based on this quantity. The characteristics of the annual variation have been obtained by means of regression, employing a regression model containing an offset, a linear term, the semi-annual and annual variation as well a QBO (quasi-biennial oscillation) term (for more details please see Lossow et al., 2017). The largest stratospheric annual variability is found in the polar regions and close to the tropopause. In the polar regions this variability is primarily due to the strong annual variation of the vertical advection. In the Antarctic lower stratosphere the annual variation of dehydration contributes significantly to the annual variation of water vapour. The large variability close to 


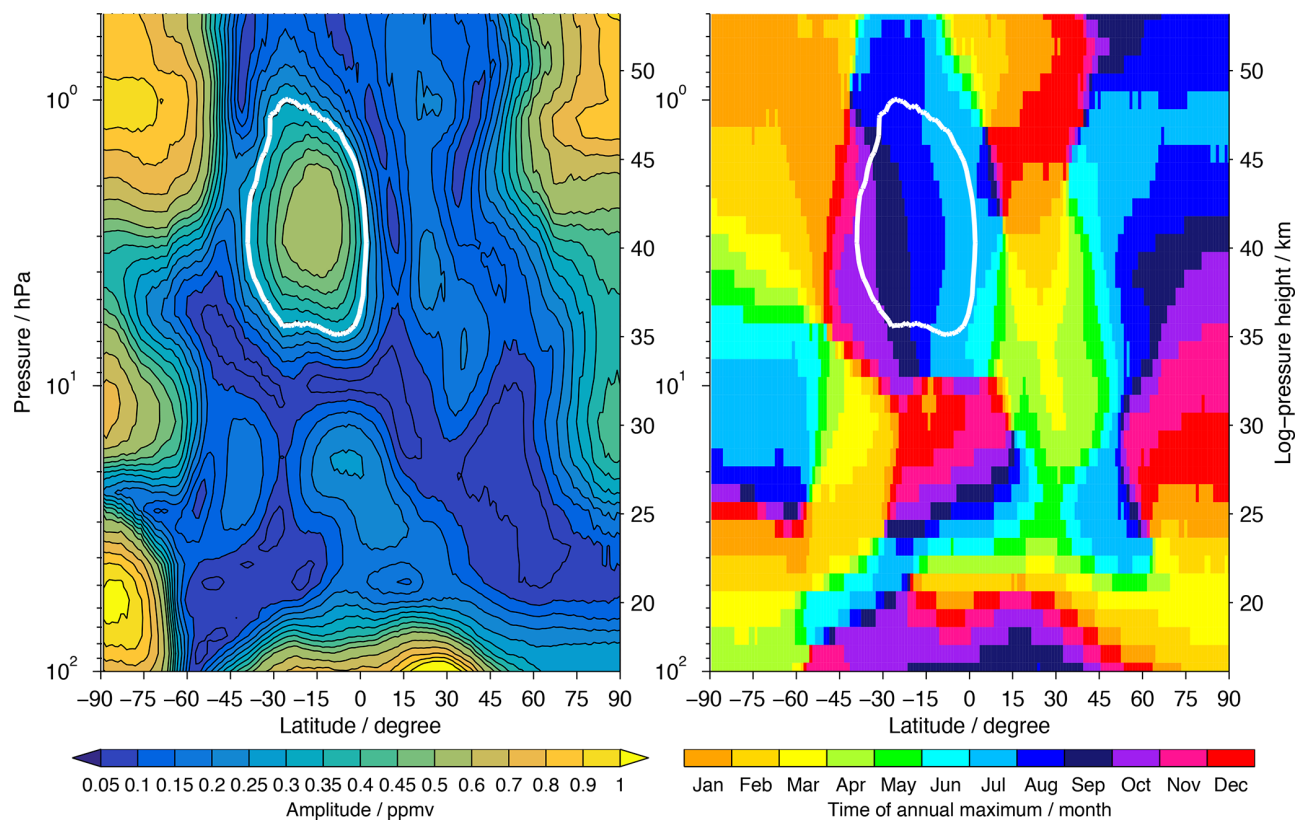

Figure 1. Characteristics of the annual variation in water vapour based on MIPAS observations from 2005 to 2012 . Panel (a) shows the amplitude as function of latitude and altitude. In (b) the phase is given, expressed by the month of a calendar year in which the annual maximum occurs. The white contour line indicates the region in which the amplitude of the enhanced annual variation is half of its peak amplitude. The data set has been binned into $5^{\circ}$ latitude bins using a $1^{\circ}$ grid.

the tropopause is on one hand due to the annual variation of dehydration at the tropical cold-point tropopause. Horizontal transport conveys this variation to higher latitudes (Ploeger et al., 2013). On the other hand variations of the tropopause height, the strong vertical variation of water vapour in the tropopause region and the finite vertical resolution of the data retrieved from the satellite observations (which is typically between 3 and $4 \mathrm{~km}$ ) cause an increased annual variation close to the tropopause. The only other region exhibiting a substantial annual variation is located in the middle and upper stratosphere in the southern tropics and subtropics. Due to its isolated nature, this feature resembles an island in the ocean, motivating the term used in the paper title. The annual variation maximises at about $15^{\circ} \mathrm{S}$ in the altitude range between 3 and $2 \mathrm{hPa}(\sim 40.5-43.5 \mathrm{~km})$. The MIPAS data exhibit an overall peak amplitude of $0.58 \mathrm{ppmv}$. The data sets compared within the second SPARC water vapour assessment (WAVAS-II) indicate on average a peak amplitude of almost $0.65 \mathrm{ppmv}$ and a corresponding standard deviation of 0.1 ppmv (not shown here, Lossow et al., 2017). The white contour line in Fig. 1 indicates where the amplitude of the enhanced annual variation has decreased to the half of its peak amplitude. Based on this criterion the enhanced annual variation extends from $38^{\circ} \mathrm{S}$ to $2^{\circ} \mathrm{N}$ in latitude and from 6 to $1 \mathrm{hPa}(\sim 38-48.5 \mathrm{~km})$ in altitude. The phase of the enhanced annual variation shows a distinct latitude dependence, with the annual maximum shifting from July close to the Equator to September in the subtropics.
There is a corresponding feature in the Northern Hemisphere. However, it is distinctively weaker and occurs at higher latitudes. The MIPAS observations indicate a peak variation of somewhat more than $0.2 \mathrm{ppmv}$ between 20 to $25^{\circ} \mathrm{N}$ slightly below $4 \mathrm{hPa}(\sim 38.5 \mathrm{~km})$. Different data sets exhibit a distinct variation in the peak location in the Northern Hemisphere, in particular with respect to the altitude. Also, the location is rather dependent on the actual approach chosen to derive the characteristics of the annual variation (see Sect. 5.3 of Lossow et al., 2017).

To illustrate the special character of the enhanced annual variation in water vapour in the middle and upper stratosphere, Fig. 2 shows the characteristics of the annual variation in the mesosphere. These results are based on observations of the Sub-Millimetre Radiometer (SMR) aboard the Odin satellite (Murtagh et al., 2002) from 2001 to 2014. More information on the SMR water vapour measurements can be found in Lossow et al. (2008). Below about $0.005 \mathrm{hPa}$ $(\sim 85.5 \mathrm{~km})$ the largest annual variation is found in the polar regions, similarly to the stratosphere. However, no isolated maximum can be found in the southern tropics and subtropics. Instead, the annual variation typically decreases towards lower latitudes and actually minimises around $15^{\circ} \mathrm{S}$ at altitudes above $0.12 \mathrm{hPa}(\sim 63 \mathrm{~km})$. This indicates a clear interhemispheric asymmetry primarily induced by differences in the forcing of the mesospheric pole-to-pole circulation by gravity waves (e.g. Siskind et al., 2003; Smith, 2012).

In Fig. 3 the MIPAS altitude-time section of water vapour for the latitude band between 18.5 and $13.5^{\circ} \mathrm{S}$ is shown. In 


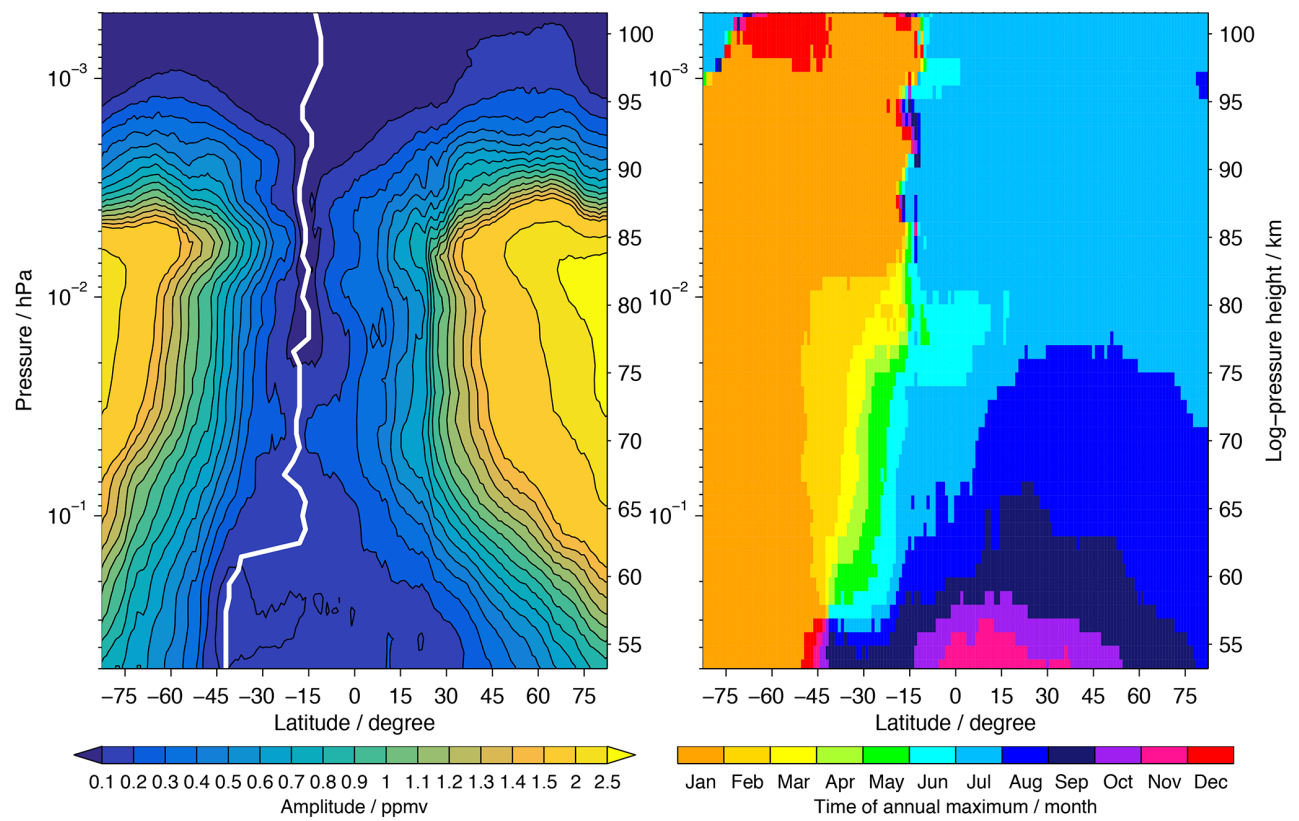

Figure 2. The annual variation of mesospheric water vapour based on observations by Odin/SMR (2001-2014). Note the different contour levels for the amplitudes as in Fig. 1. Also, the latitude coverage is a bit smaller. The white line in (a) indicates the latitude with the minimum amplitude. The data have been averaged over latitude bins of $10^{\circ}$ due to the lower horizontal sampling of the SMR observations compared to MIPAS, but still a $1^{\circ}$ grid is used.

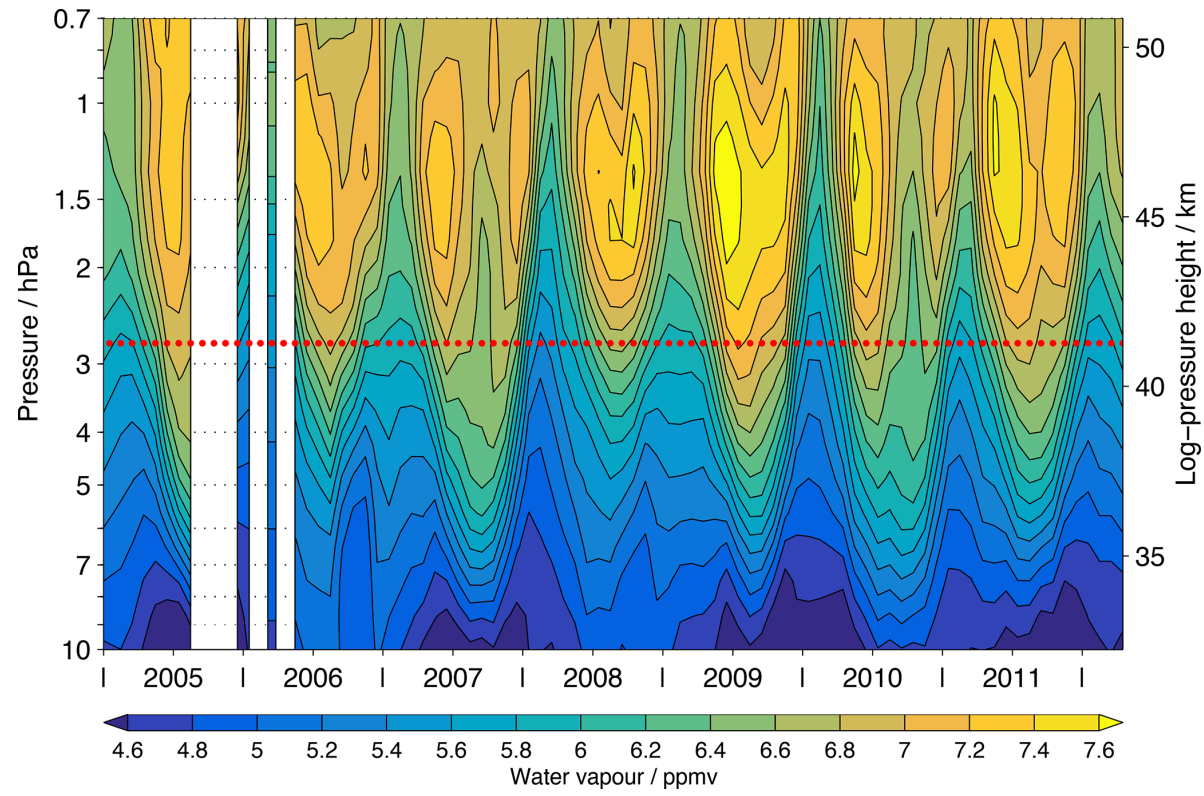

Figure 3. The MIPAS altitude-time section of water vapour for the latitude band between 18.5 and $13.5^{\circ} \mathrm{S}$. In contrast to Fig. 1 only the altitude range between 10 and $0.7 \mathrm{hPa}(\sim 32-51 \mathrm{~km})$ is considered here. The red dotted line shows the altitude (i.e. $2.7 \mathrm{hPa}, \sim 41.5 \mathrm{~km})$ at which the amplitude of the annual variation in this latitude band exhibits its maximum according to Fig. 1. White areas indicate that no MIPAS data were available.

this latitude band the MIPAS observations show the overall peak amplitude of the enhanced annual variation, namely at a pressure level of $2.7 \mathrm{hPa}(\sim 41.5 \mathrm{~km})$. This level is indicated by the red dashed line in the figure. The observations show that at altitudes around $2.7 \mathrm{hPa}(\sim 41.5 \mathrm{~km})$ the annual minimum typically occurs in the first months of the year (austral summer and autumn). The annual maxima, in contrast, can be in general observed early in the second half of the year 


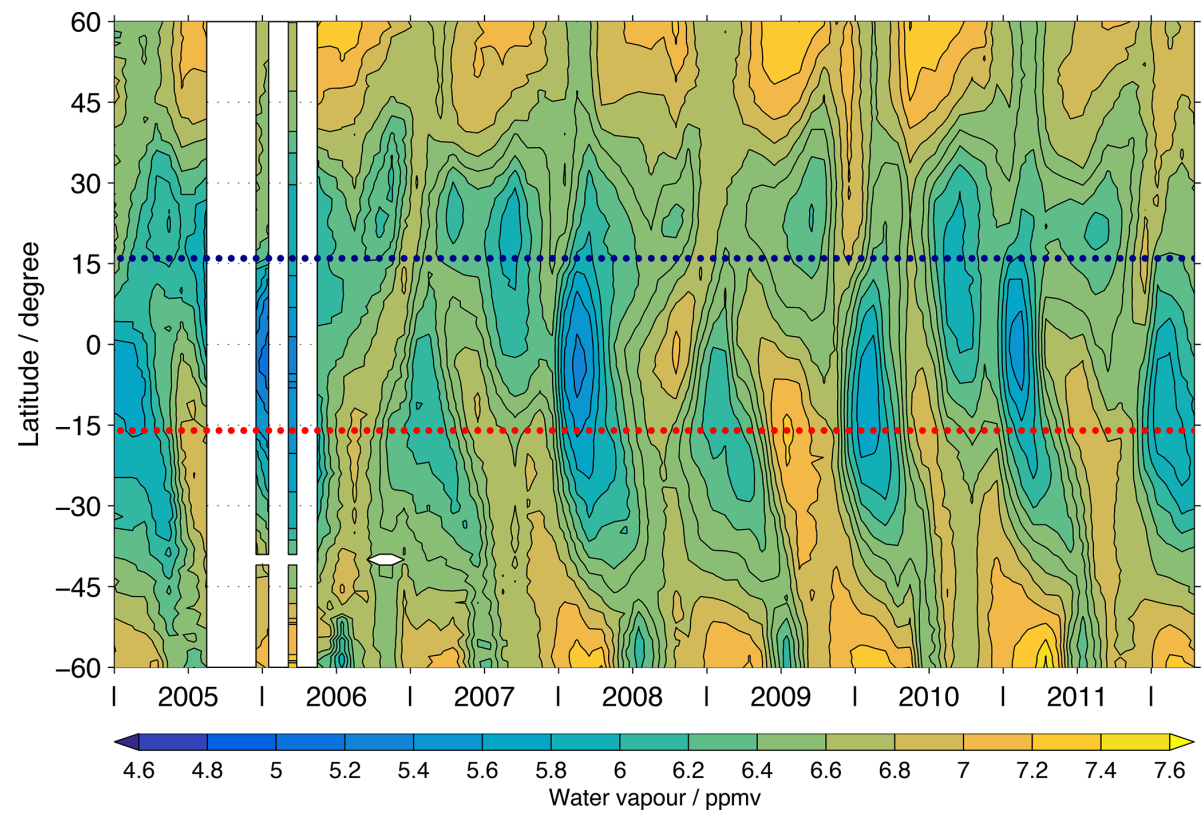

Figure 4. Latitude-time section of water vapour at $2.7 \mathrm{hPa}(\sim 41.5 \mathrm{~km})$ as observed by MIPAS. Only latitudes from $60^{\circ} \mathrm{S}$ to $60^{\circ} \mathrm{N}$ are considered. The red dotted line indicates the latitude at which the annual variation in the southern tropics and subtropics at this pressure level maximises. For comparison a dark blue dotted line is added at the corresponding latitude in the Northern Hemisphere.

(austral winter and spring), as shown in the right panel of Fig. 1. At $2.7 \mathrm{hPa}(\sim 41.5 \mathrm{~km})$ some apparent semi-annual variation is also visible, in particular in 2007 and 2010. In 2007 the annual maximum occurs a little bit later than normal, while in 2010 it appears as early as late in the first half of the year. Higher up, between 1.5 and $1 \mathrm{hPa}(\sim 45.5-48.5 \mathrm{~km})$ the semi-annual variation is even more pronounced.

For a final description, Fig. 4 shows the latitude-time section of water vapour at a pressure level of $2.7 \mathrm{hPa}$ $(\sim 41.5 \mathrm{~km})$. A red dashed line is drawn at $16^{\circ} \mathrm{S}$ to indicate the latitude at which the enhanced annual variation derived from the MIPAS observations exhibits its peak amplitude in the Southern Hemisphere. For the sake of comparison, a dark blue dotted line is drawn at the corresponding latitude in the Northern Hemisphere. The figure indicates a clear interhemispheric asymmetry in the tropical band. The extreme volume mixing ratios have a clear tendency to be shifted towards the Southern Hemisphere. The low volume mixing ratios at $15^{\circ} \mathrm{S}$ during austral summer and autumn extend towards the Antarctic, where they can be observed in winter. The same kind of behaviour can also be observed for the high volume mixing ratios just with the corresponding time shift. Such an overall pattern is, however, not as obvious in the Northern Hemisphere, illustrating once more interhemispheric differences in the processes, giving rise to the water vapour distribution at this altitude. Beyond that, a strong interannual variability is visible in the tropical water vapour volume mixing ratios. Most prominently the annual minimum exhibits very low ratios in 2006, 2008 and 2011, while in 2007 and 2009 the ratios are clearly higher. This variability is predominantly related to the QBO, which has a local maximum in this region (Randel et al., 1998; Lossow et al., 2017).

\section{Discussion}

The analysis of the annual variation amplitude in water vapour shows an isolated maximum in the southern tropics and subtropics in the middle and upper stratosphere. The annual variation typically peaks at about $15^{\circ} \mathrm{S}$ in latitude and between 3 and $2 \mathrm{hPa}$ in altitude in the observations. In the following discussion we focus first on the attribution of this enhanced annual variation. Initially this will be based on additional observational results. For a more advanced attribution we use the model results from EMAC. In the Northern Hemisphere a weaker counterpart of the enhanced annual variation in the south can be observed. This counterpart typically peaks at higher latitudes and lower altitudes than in the Southern Hemisphere. In the second part of the discussion will focus on the reasons for this interhemispheric asymmetry.

\subsection{Attribution}

In principle both chemical and dynamical reasons or their combination could explain this enhanced annual variation. To start the attribution discussion of this feature, Fig. 5 shows the amplitude of the annual variation for other longer-lived trace gases observed by MIPAS (Plieninger et al., 2016; Eckert et al., 2016; Chirkov et al., 2016), again as function of latitude and altitude. The results were obtained using the same approach as for the water vapour results presented in Fig. 1. 

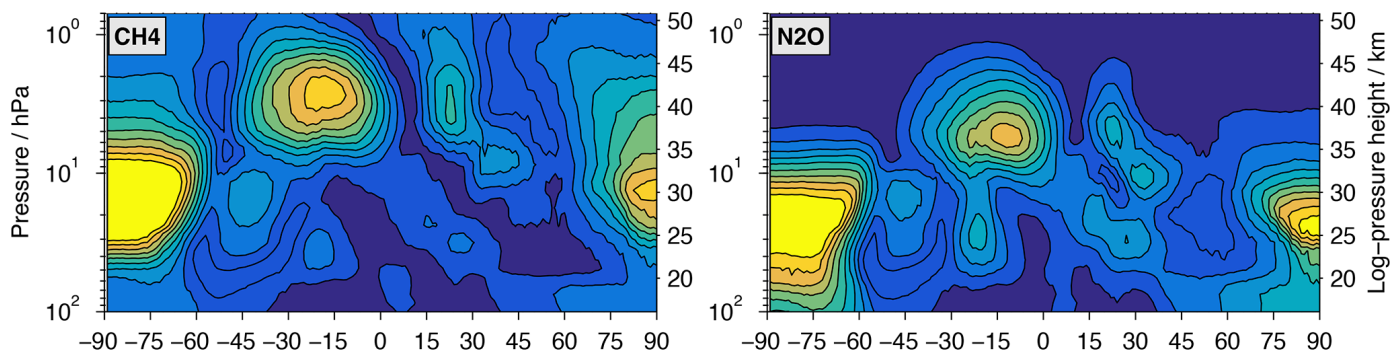

$\begin{array}{llllllllllllll}0.03 & 0.06 & 0.09 & 0.12 & 0.15 & 0.18 & 0.21 & 0.24 & 0.27 & 0.3\end{array}$ Amplitude / ppmv
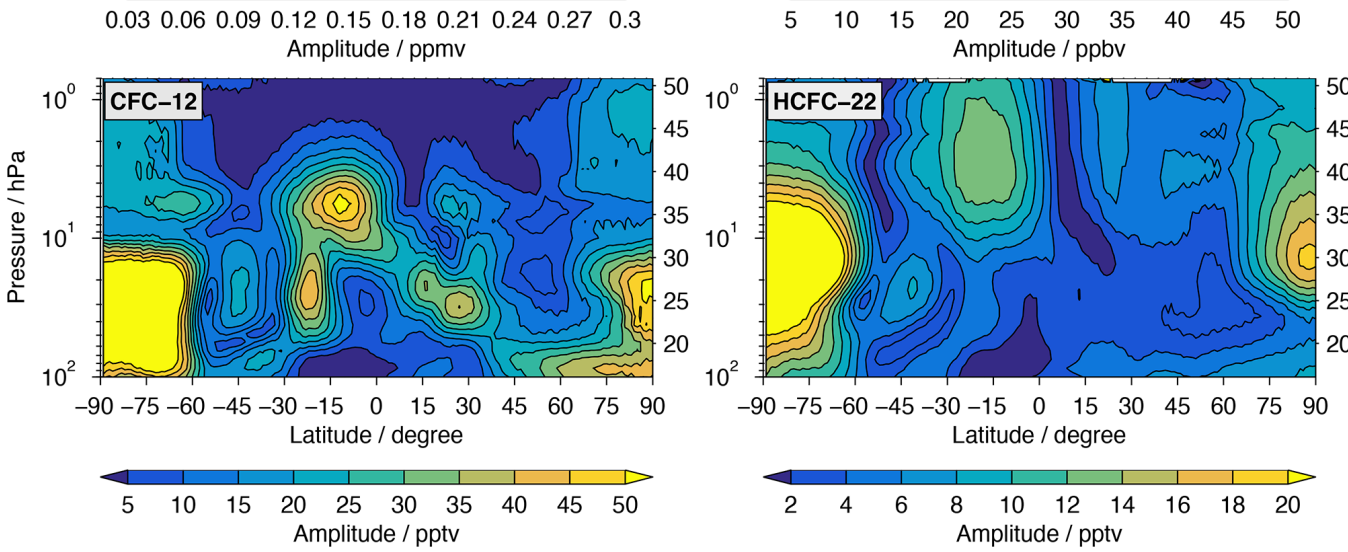

Figure 5. The amplitude of the annual variation in other longer-lived trace gases observed by MIPAS.

In all trace gases a similar enhanced annual variation to that seen in water vapour is observed in the middle and upper stratosphere in the southern tropics and subtropics. The existence of this feature in methane could be expected due to its tight chemical relationship to water vapour, in line with previous observations reported by Holton and Choi (1988) and Randel et al. (1998). The existence of the feature in the other trace gases clearly indicates that dynamics plays a larger role than methane chemistry in the explanation of the enhanced annual variation in water vapour. The exact location of the peak variation differs a bit for the different trace gases, implying some importance of the actual chemistry and the resulting gradients in the distribution of the individual trace gases. For both nitrous oxide $\left(\mathrm{N}_{2} \mathrm{O}\right)$ and $\mathrm{CFC}-12$ $\left(\mathrm{CCl}_{2} \mathrm{~F}_{2}\right)$, the annual variation peaks at $12^{\circ} \mathrm{S}$ between 5 and $6 \mathrm{hPa}(\sim 36-37 \mathrm{~km})$. For HCFC-22 $\left(\mathrm{CHClF}_{2}\right)$ the peak is located at $18^{\circ} \mathrm{S}$ and close to $3 \mathrm{hPa}(\sim 40.5 \mathrm{~km})$. This location is probably affected by the coarse vertical resolution of the HCFC-22 data, close to the upper-altitude limit where a reasonable retrieval is possible. The resolution exceeds $10 \mathrm{~km}$ (see Figs. 2 and 3 of Chirkov et al., 2016), explaining why the enhanced annual variation is much more extended in the altitude domain than for the other trace gases.

Figure 6 shows the MIPAS time series of water vapour (blue, left axis) for the latitude band between 18.5 and $13.5^{\circ} \mathrm{S}$ and $2.7 \mathrm{hPa}(\sim 41.5 \mathrm{~km})$ in relation to the corresponding time series of the other longer-lived trace gases considered in the last figure. In all panels of the figure a pronounced anti-correlation between water vapour and the other trace gases can be observed. The correlation coefficients are between -0.87 and -0.96 for the comparisons with methane, nitrous oxide and CFC-12. The comparison with the HCFC-22 time series yields a lower correlation coefficient, i.e. -0.59 . As argued above this reduction is probably due to the coarse vertical resolution of the HCFC-22 data, while the resolution of the water vapour data is about $5 \mathrm{~km}$. A possible explanation for the observed anti-correlations is vertical advection. While the water vapour volume mixing ratio increases with altitude in the middle and upper stratosphere, the ratio of the other trace gases decreases with altitude. This would be in agreement with the considerations by Jackson et al. (1998). However, meridional advection is also a possible explanation. The meridional gradients of water vapour are approximately the same size as the annual variation. Also, the meridional gradients of water vapour are anticorrelated to the meridional gradients of the other trace gases (not shown here).

From the observations presented in the two previous figures it has been possible to discern the importance of advection for the enhanced annual variation in water vapour. In the discussion further on we use EMAC simulation results as described in the Introduction. For comparison with the observations (see Fig. 1) Fig. 7 shows the amplitude and phase of the annual variation derived from the simulations. Overall, a good agreement between the observations and simulations is found. In the simulations, the enhanced annual variation 

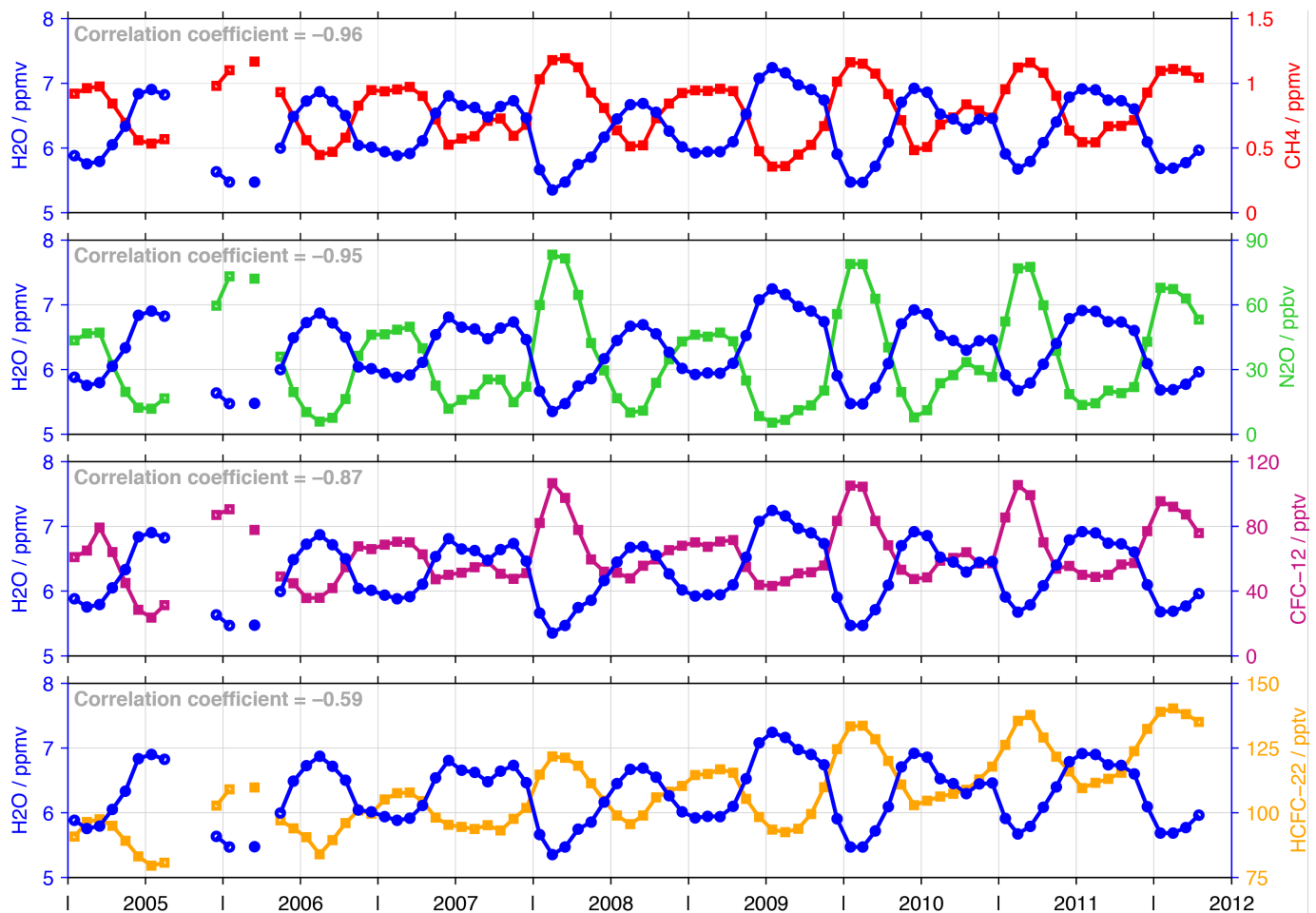

Figure 6. Comparison of the water vapour time series (blue, always left axis) with the time series of methane (red), nitrous oxide (green), CFC-12 (violet red) and HCFC-22 (orange). All data consider MIPAS observations at $2.7 \mathrm{hPa}$ for the latitude band from 18.5 to $13.5^{\circ} \mathrm{S}$. The correlation between the time series is indicated in the upper-left corner.

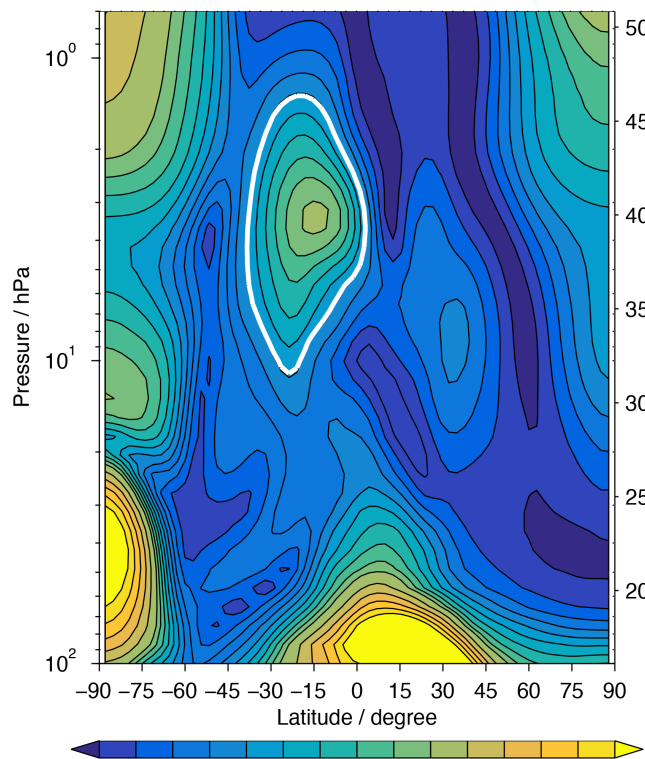

$0.050 .10 .150 .20 .250 .30 .350 .40 .450 .5 \quad 0.6 \quad 0.7 \quad 0.8 \quad 0.9 \quad 1$ Amplitude / ppmv

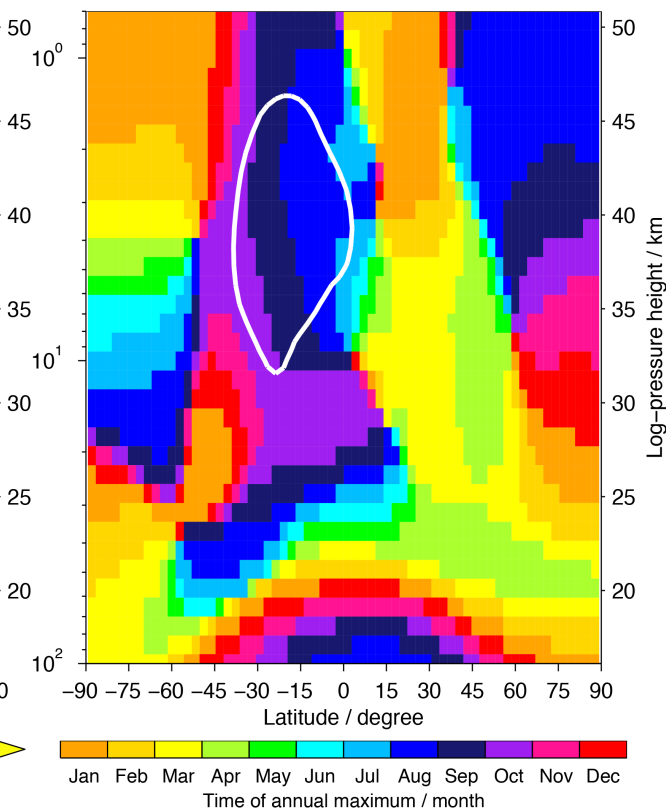

Figure 7. As Fig. 1 but based on EMAC simulations for the time period from 2008 to 2012. 

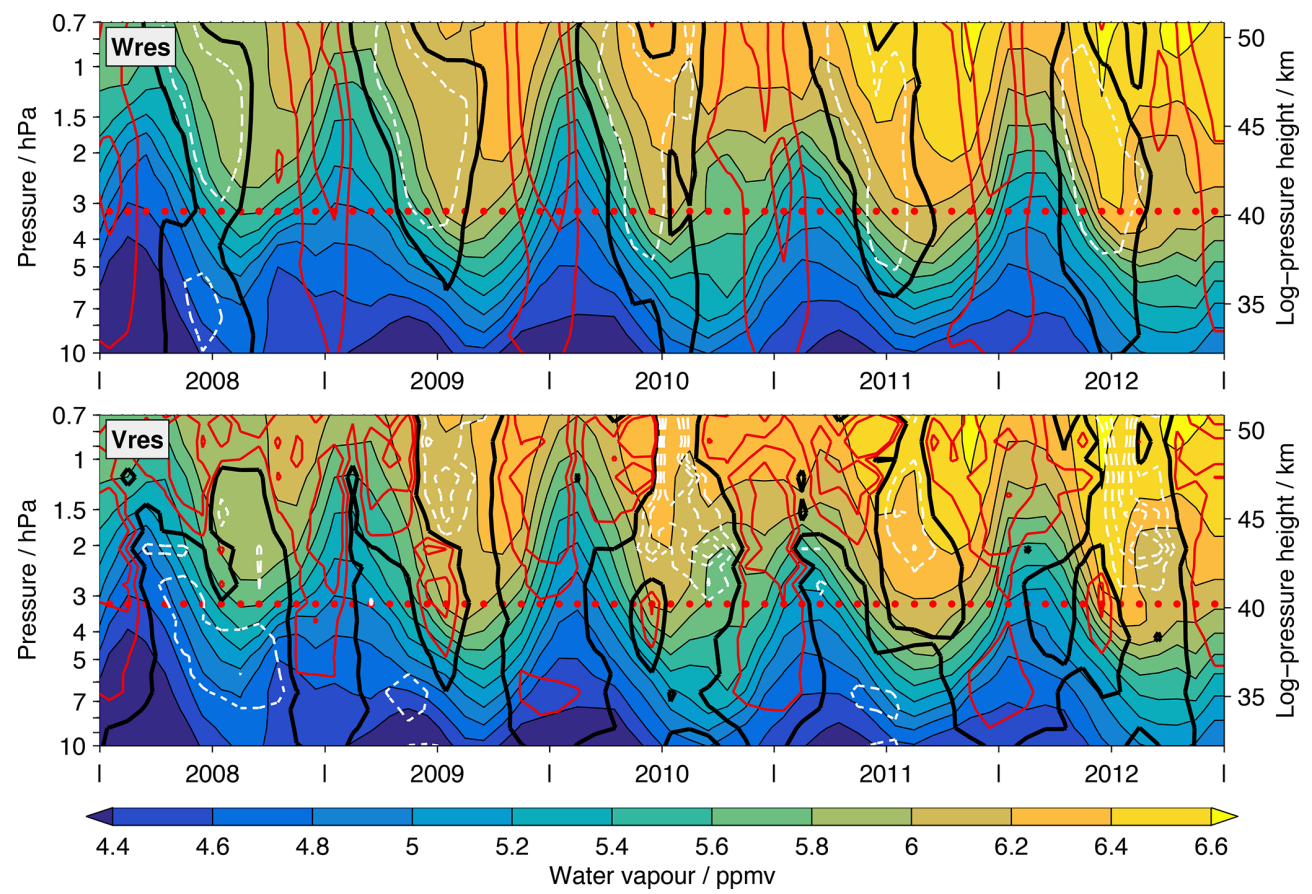

Figure 8. The EMAC altitude-time section of water vapour at $15^{\circ} \mathrm{S}$. In (a) the residual vertical velocity is overlaid, while in (b) the residual meridional velocity is considered. The black contour represents the zero wind line. Red solid contours show positive winds (in steps of $1 \mathrm{~mm} \mathrm{~s}^{-1}$ for the vertical wind and $0.25 \mathrm{~m} \mathrm{~s}^{-1}$ for the meridional wind), while negative winds are indicated by white dashed contours (in steps of $0.5 \mathrm{~mm} \mathrm{~s}^{-1}$ for the vertical wind and $0.5 \mathrm{~m} \mathrm{~s}^{-1}$ for the meridional wind). The red dotted line marks the pressure level where the enhanced annual variation in EMAC water vapour maximises. Note the different contour levels with respect to the corresponding figure showing the MIPAS observations (Fig. 3).

also extends from $38^{\circ} \mathrm{S}$ to $2^{\circ} \mathrm{N}$ in latitude. In altitude, the feature ranges from 10 to $1.5 \mathrm{hPa}(\sim 32.5-45.5 \mathrm{~km})$, indicating a larger vertical extent and a slight downward shift compared to the observations. The simulations exhibit the peak variation at $15^{\circ} \mathrm{S}$ and $3.2 \mathrm{hPa}(\sim 40 \mathrm{~km})$. The peak amplitude is 0.51 ppmv. This is somewhat lower than in the MIPAS observations, but still within the range of the different observational data sets compared in the second SPARC water vapour assessment (Lossow et al., 2017). The amplitude agreement at $15^{\circ} \mathrm{S}$ is within $\pm 0.05 \mathrm{ppmv}$ right below the peak altitude down to about $6 \mathrm{hPa}$. Above and below this altitude region the amplitude differences between the observations and simulations are larger, consistent with the differences in the vertical extent of the enhanced annual variation. In terms of the phase the observations and simulations agree within \pm 1 month. However, there is a tendency for the annual maximum to occur later in the simulations. For the northern hemispheric counterpart of the feature, similar differences in the amplitude and phase can be found. Interestingly, the annual maximum derived from simulations has here a tendency to occur earlier than in the observations. Overall, this is arguably not a perfect comparison, neither in terms of the temporal and spatial consistency between the observations and simulations nor in terms of the quantitative agreement. Nonetheless, the generally good agreement between the sim- ulations and observations allows the attribution of the enhanced annual variation with a certain degree of confidence from the simulation side.

Figure 8 shows the EMAC altitude-time section at $15^{\circ} \mathrm{S}$. In the upper panel contours of the residual vertical velocity are overlaid, in the lower panel the residual meridional velocity is considered. Positive winds are given by red solid contours and negative winds by white dashed contours. Overall, the water vapour structure in EMAC is very similar to that in the observation (see Fig. 3). However, there are differences in the absolute amount of water vapour, with the simulations showing lower volume mixing ratios than the observations. Comparing the temporal development of water vapour and the residual vertical velocity reveals some coherent behaviour of these two quantities. Increases (decreases) in water vapour roughly go along with downwelling (upwelling). At the peak altitude of the enhanced annual variation (i.e. $3.2 \mathrm{hPa}$ ) the correlation coefficient between water vapour and the vertical velocity amounts to -0.49 . A more detailed look indicates that increases in water vapour actually precede downwelling by approximately 2 months at the peak altitude. Higher up, at $1 \mathrm{hPa}$, no such delay is observed. Instead the delay between increases in water vapour and downwelling increases with decreasing altitude. Decreases in water vapour are more directly related to upwelling. Occasion- 


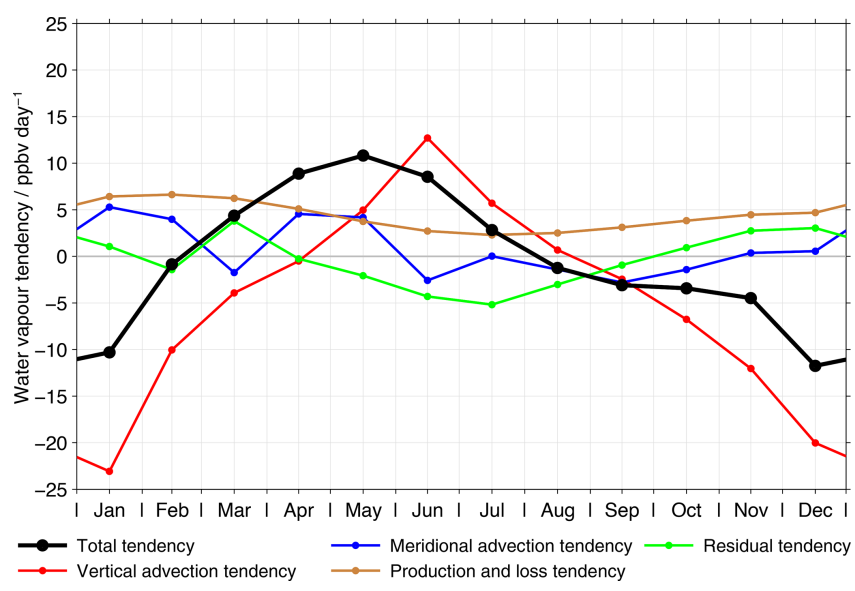

Figure 9. The water vapour tendencies at $15^{\circ} \mathrm{S}$ and $3.2 \mathrm{hPa}$ derived from the EMAC simulations using climatological values and based on the time period between 2008 and 2012.

ally there is also a delay between these two quantities, in particular below the peak altitude, but not as obvious as between water vapour increases and downwelling. Beyond that, some apparent QBO variation can be found in the downwelling, extending to lower altitudes in 2008, 2010 and 2012 than in 2009 and 2011. Overall, this indicates that vertical advection definitely plays a role in the enhanced annual variation, but other processes are clearly needed.

Also, between the residual meridional velocity and the water vapour distribution some coherent behaviour can be observed. Most prominently, the decrease in water vapour from the annual maximum to the minimum is typically accompanied by northward winds. Southward winds prevail during the time of the annual maximum. In addition, increases in water vapour below $2 \mathrm{hPa}(\sim 43.5 \mathrm{~km})$ coexist with southerly winds. At the peak altitude of the enhanced annual variation, the correlation between the residual meridional wind and water vapour is not statistically significant (correlation coefficient is -0.02). In summary, it can be concluded that also the meridional advection contributes to the enhanced annual variation feature. However, this does not universally apply throughout the year. The meridional advection influence is greatest during austral summer.

For a more detailed attribution Fig. 9 shows the EMAC water vapour budget at the peak location of the enhanced annual variation at $15^{\circ} \mathrm{S}$ and $3.2 \mathrm{hPa}$, using the tendencies of the continuity equation given below:

$$
\begin{aligned}
& \underbrace{\frac{\partial \bar{\chi}}{\partial t}}_{\text {total tendency }}=\underbrace{}_{\text {meridional advection tendency }} \\
&+ \underbrace{-\frac{\bar{v}^{*}}{a} \cdot \frac{\partial \bar{\chi}}{\partial \phi}}_{\text {vertical advection tendency }} \\
&+ \underbrace{P-\bar{w}^{*} \cdot \frac{\partial \bar{\chi}}{\partial z}}_{\text {production and loss tendency }} \\
&+\underbrace{R}_{\text {residual tendency }} \cdot
\end{aligned}
$$

Here $\bar{\chi}$ denotes the water vapour zonal mean volume mixing ratio, $t$ is the time, $\phi$ the latitude and $z$ the altitude. $a=111195 \mathrm{~m} \mathrm{deg}^{-1}$ gives the conversion between distance in latitude and the geometric scale. $\bar{v}^{*}$ and $\bar{w}^{*}$ describe the residual meridional and vertical velocity, respectively. $P-L$ represents the chemical production minus loss rate, while $R$ is the residual tendency. This tendency is not calculated explicitly here; instead we calculate the residual by balancing the continuity equation. We ascribe the residual tendency to eddy transport (i.e. mixing), which is an assumption, however. This term certainly contains some contribution from numerical diffusion and possibly a contribution arising from uncertainties in the budget reconstruction. Different studies have shown that resolved eddy transport is at least the largest contribution to the residual, for example for carbon monoxide and ozone in the lower tropical stratosphere (Abalos et al., 2013) or for age of air in the lower stratosphere (Dietmüller et al., 2017). The data shown in Fig. 9 are based on averages over the time period from 2008 to 2012. The temporal behaviour of the total tendency is best resembled by that of the vertical advection tendency. The most prominent differences concern the overall amplitude of the annual variation and the time when the annual extrema occur. For the vertical advection tendency the amplitude is larger and its annual extrema occur 1 month later than for the total tendency. This confirms the dominant role of vertical advection in the enhanced annual variation of water vapour in this region, but it also indicates that the other tendencies have some importance for the exact characteristics of this feature. In particular, in austral summer the other tendencies exhibit positive values, which both weakens the overall annual variation of water vapour and adjusts the time of the annual minimum in the total tendency. During austral winter the residual tendency is negative, also contributing distinctively to the reduction of the annual variation. The time of annual maximum in the total tendency is adjusted again by a combination of meridional advection, chemistry and eddy transport.

Figure 10 provides an overview of the vertical structure of the different tendencies at $15^{\circ} \mathrm{S}$, again based on the climatology from 2008 to 2012. The total tendency does not exhibit much altitude variation in its sign. Exceptions occur from July to November, resulting in a prominent semi-annual variation above about $2 \mathrm{hPa}(\sim 43.5 \mathrm{~km})$, in agreement with the 

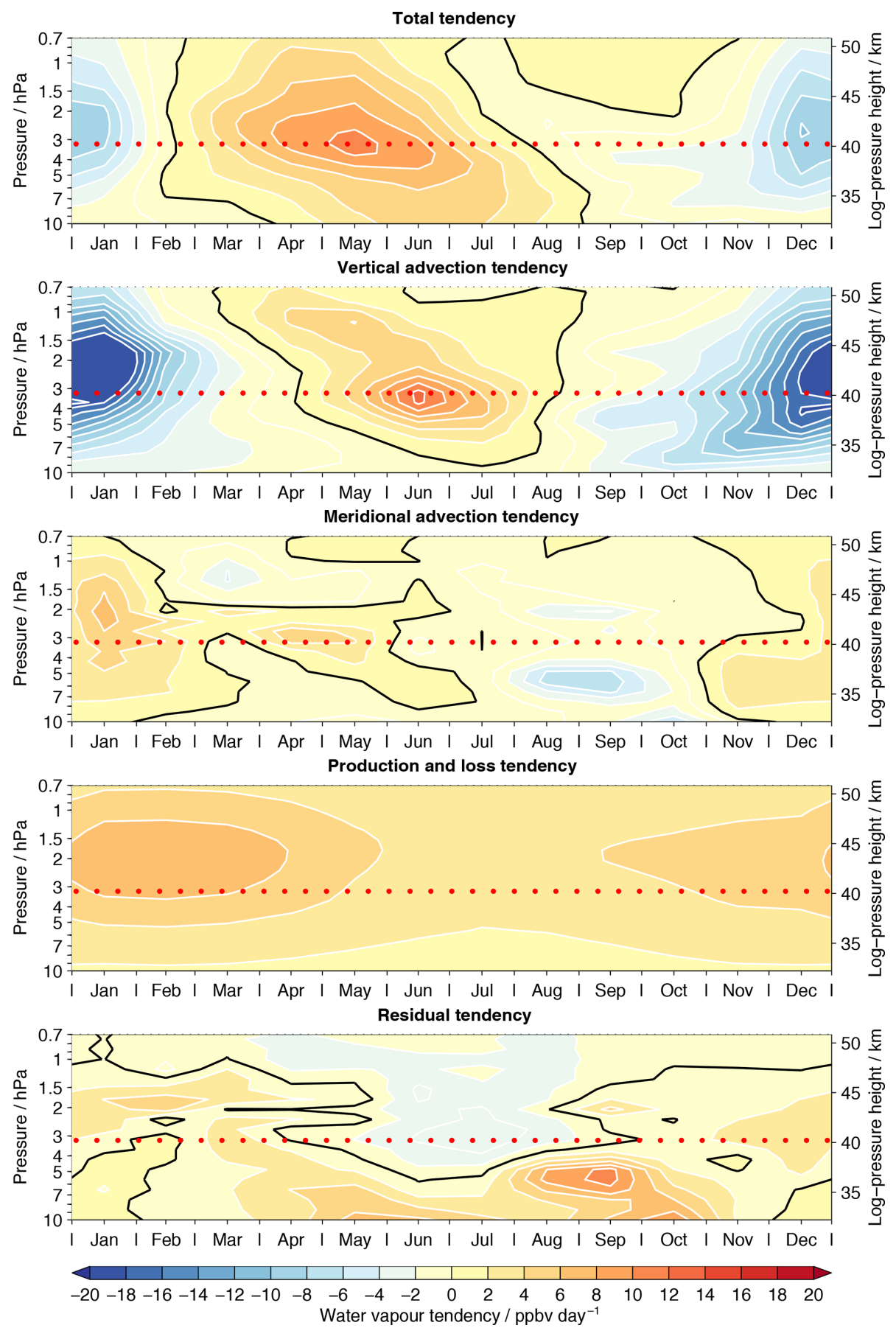

Figure 10. An overview of the vertical structure of the different tendencies at $15^{\circ} \mathrm{S}$. As in Fig. 9 the results are based on climatological averages for the time period between 2008 and 2012. The black contour indicates the zero line.

observations (see Fig. 3). The vertical advection tendency is also rather constant in sign for the considered altitude range. While the largest positive tendencies occur close to the peak altitude of the enhanced annual variation, the largest negative tendencies can be observed a bit higher up. The temporal shift of the annual minimum to its equivalent in the total tendency is visible over a larger altitude range. For the annual maximum the corresponding shift is altitude-dependent and minimises around $1 \mathrm{hPa}(\sim 48.5 \mathrm{~km})$. This is in agreement with the discussion of Fig. 8 regarding the delay between water vapour increases and downwelling. The meridional advection tendency shows a prominent altitude variation of its sign from March to June. In December and January the tendencies are positive at most altitudes, contributing to the re- 
duction of the annual variation. The tendency of the chemical production and loss is positive at all altitudes. The largest tendencies can be observed around $2 \mathrm{hPa}(\sim 43.5 \mathrm{~km})$ during the first months of the year. The residual tendency is primarily negative above $1 \mathrm{hPa}(\sim 48.5 \mathrm{~km})$ and primarily positive below $5 \mathrm{hPa}(\sim 37 \mathrm{~km})$. In between, the tendencies are negative from May to August and positive for the rest of the year. In summary, there is some altitude dependence in the budget of the enhanced annual variation at $15^{\circ} \mathrm{S}$. While the vertical advection clearly remains the dominant process, the relative importance of the meridional advection and the eddy transport particularly vary with altitude. However, the reduction of the annual variation in austral summer produced by the combination of meridional advection, eddy transport and chemistry continues to be a general characteristic.

Based on the discussion so far it is clear that advection, chemistry and eddy transport all contribute to the enhanced annual variation. In the next step we assess which combination of processes is essential for reproducing the enhanced annual variation and its structure and which processes just cause minor adjustments to the overall picture. For this we compare the annual variation of the total tendency with the variation of the individual tendencies and their combinations, based on regressions of the data from 2008 to 2012. The results are shown in Fig. 11. As expected, the annual variation of the total tendency exhibits the same enhanced annual variation feature as water vapour itself (panel a). The annual variation of the vertical advection tendency shows some resemblance to the total tendency (panel b). However, the amplitudes in the middle and upper stratosphere in the southern tropics and subtropics are considerably larger for the most part. These large amplitudes also clearly extend into the midlatitudes. A similar picture can be observed in the Northern Hemisphere. Considering the annual variation of the vertical and meridional advection tendency combined (referred to as total advection tendency) modifies the picture obtained for the vertical advection tendency only slightly (panel c). It becomes apparent that advection alone cannot explain the enhanced annual variation and its structure. Also, in combination with the chemical production and loss, a complete explanation is not possible (panel d). Inevitably, this indicates that the eddy transport, described by the residual tendency, must play an important role. Panel (e) first shows the annual variation of this tendency individually. In the middle and upper stratosphere in the southern tropics and subtropics the variation is small and clearly different than those seen for the other tendencies. Yet, the annual variation of the advection tendencies combined with the residual tendency yields an almost identical structure as observed for total tendency (panel f). Thus, advection and eddy transport are the essential processes that explain the enhanced annual variation and its structure, while the chemical production and loss just cause a second-order modification.

\subsection{Interhemispheric differences}

The remaining part of the discussion will focus on the reasons for the interhemispheric differences. Given the importance of the vertical advection for the enhanced annual variation a relation to the interhemispheric differences in the Brewer-Dobson circulation, which is weaker in austral winter, is rather probable. For illustration, Fig. 12 shows the EMAC latitude-time section of water vapour at $3.2 \mathrm{hPa}$ $(\sim 40 \mathrm{~km})$ with contours of the residual vertical velocity overlaid in the upper panel and the residual meridional velocity in the lower panel. The red dotted line again indicates the latitude where the enhanced annual variation maximises, while the blue dotted line indicates the corresponding latitude in the Northern Hemisphere for comparison. As expected, a distinct interhemispheric asymmetry in the distribution of upwelling and downwelling can be observed. There are two key aspects. The weaker circulation in austral winter results in slower upwelling in the Northern Hemisphere and correspondingly in a smaller decrease in water vapour. The stronger circulation in boreal winter results in stronger upwelling in the Southern Hemisphere with a more pronounced reduction of water vapour. This quantitatively explains a larger annual cycle in the Southern Hemisphere, as noted by Jackson et al. (1998). In addition, the weaker circulation in austral winter results in a transition from upwelling to downwelling (also called the "turnaround latitude"; see Rosenlof, 1995) a bit north of the Equator, allowing the advection of moister air from above in the southern tropics and subtropics. In boreal winter, when the circulation is stronger, this transition occurs first at about $15^{\circ} \mathrm{N}$. This aspect amplifies interhemispheric differences in the annual variation even further. It explains why the feature occurs more polewards in the Northern Hemisphere and designates the northern boundary of the enhanced annual variation.

Figure 13 expands the discussion above a bit by showing all components of the water vapour budget as function of latitude at $3.2 \mathrm{hPa}(\sim 40 \mathrm{~km})$. The total tendencies at $15^{\circ}$ latitude highlight once more that the interhemispheric differences concern both the annual minimum and maximum (panel a). The same picture can also be seen in the vertical advection tendency (panel b). In general the largest absolute tendencies occur in the Southern Hemisphere. In the latitude band between 5 and $15^{\circ} \mathrm{N}$ the vertical advection tendency is almost exclusively negative, hampering the development of a substantial annual variation as underlined before. Also, in terms of the meridional advection tendency, clear interhemispheric differences can be observed (panel c). At $15^{\circ} \mathrm{S}$ the meridional advection tendency is primarily positive while at $15^{\circ} \mathrm{N}$ it is more negative. In the south this tendency contributes to a reduction of the annual variation, while in the north it plays more of a role in the semi-annual variation observable in the total tendency. There are some smaller interhemispheric differences in the production and loss tendency. However, this term seems to primarily reflect the solar insola- 

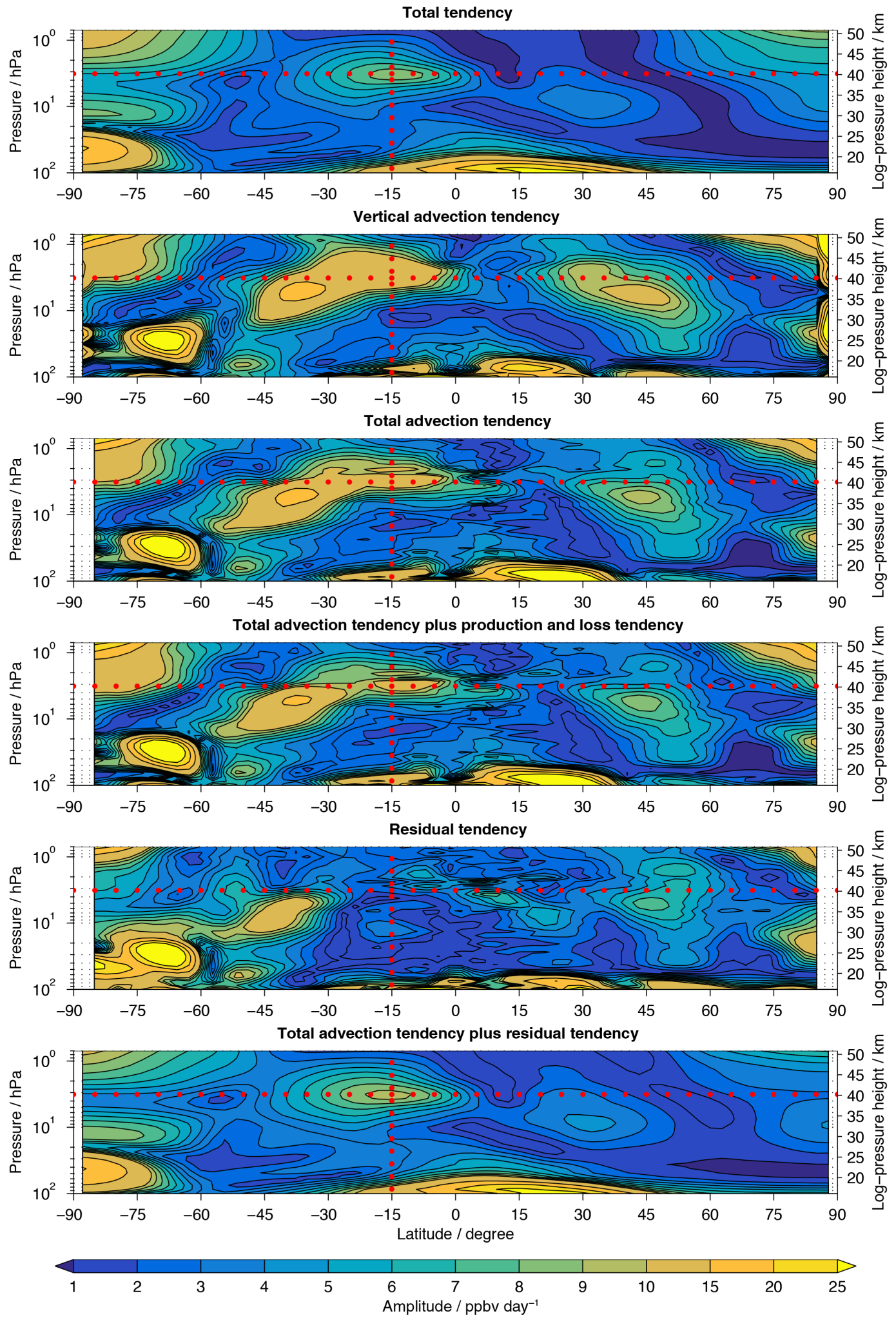

Figure 11. The top panel shows the amplitude of the annual variation of the total tendency in water vapour. As with water vapour, it shows an isolated maximum in the middle and upper stratosphere in the southern tropics and subtropics. The panels below show the annual variation amplitude for different tendencies and their combinations. It shows that only the total advection tendency in combination with the residual tendency reproduces the enhanced annual variation in its entire structure. The red dotted lines mark the peak position of the enhanced annual variation for guidance. 

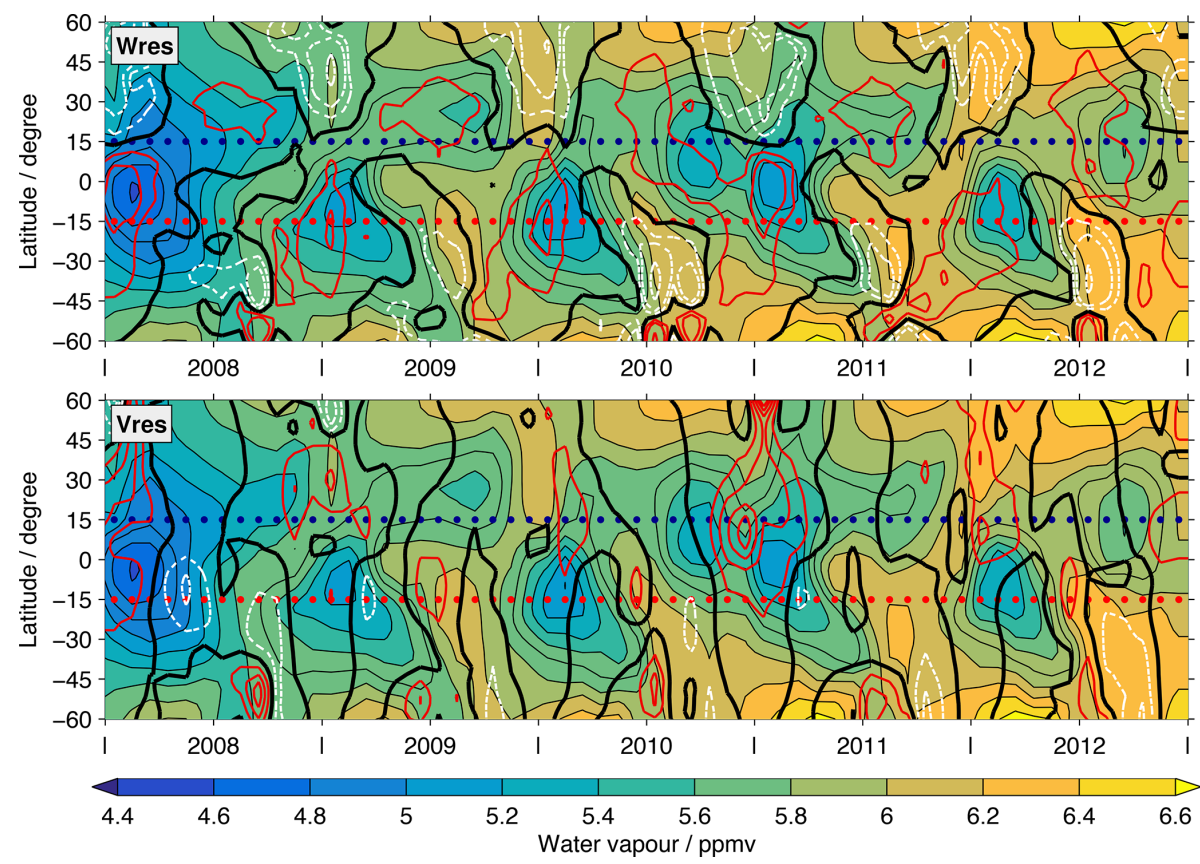

Figure 12. The EMAC latitude-time section of water vapour at a pressure level of $3.2 \mathrm{hPa}$. As in Fig. 8 the residual vertical (a) and meridional velocity (b) are overlaid. The vertical winds are given at 1,2 and $5 \mathrm{~mm} \mathrm{~s}^{-1}$ for both upwelling and downwelling. For the meridional wind, contours of $0.4 \mathrm{~m} \mathrm{~s}^{-1}$ are used. The red dotted line marks indicates the latitude where the enhanced annual variation maximises. As in Fig. 4 a dark blue dotted line is added at the corresponding latitude in the Northern Hemisphere for comparison.

tion contributing to methane oxidation as the primary source of water vapour in the upper stratosphere. The residual tendency exhibits interhemispheric differences as well. While they are not as essential as those in the vertical advection, they evidently rank in second place in general.

At last we address interhemispheric differences not at the same altitude, but at locations where the annual variation is substantial. For this Fig. 14 shows a comparison of the water vapour budget at $15^{\circ} \mathrm{S} / 3.2 \mathrm{hPa}$ and $24^{\circ} \mathrm{N} / 5.6 \mathrm{hPa}$, again using the climatological results for the time period from 2008 to 2012. The former is the location where the enhanced annual variation peaks in the EMAC simulations. The northern counterpart actually peaks at $35^{\circ} \mathrm{N}$ and $8.7 \mathrm{hPa}$ (see Fig. 7), but with regard to the observations, which show the peak at $23^{\circ} \mathrm{N}$ (see Fig. 1), a lower latitude that is also representative is considered. For a better visual comparison, the results for the Northern Hemisphere have been shifted by 6 months. For the same reason panel (a) considers the water vapour anomaly relative to the annual mean, since the absolute volume mixing ratios inevitably differ due to the different altitudes considered. As visible in the previous figure, there is an apparent semi-annual variation in the north, resulting in interhemispheric differences in the occurrence of the annual extrema. In the Southern Hemisphere substantial positive total tendencies can be observed over a longer period of time, while the level of negative tendencies is smaller in the Northern Hemisphere (panel b). In terms of vertical advection, interhemispheric differences are primarily visible in terms of the negative tendencies (panel c). The temporal behaviour is very much aligned. While the meridional advection tendency exhibits a lot of variation throughout the year in the Southern Hemisphere, the corresponding term in the Northern Hemisphere shows a well-defined annual variation (panel d). This variation is almost in anti-phase to the vertical advection tendency (the shift is 1 month) leading to some substantial compensation between these terms in the Northern Hemisphere. The differences in the production and loss tendency mostly reflect the differences in the altitude considered, with the methane oxidation being more efficient at the higher altitude (panel e; see also Fig. 10). This naturally causes some differences in the relative importance of the processes, giving rise to the annual variation in the two hemispheres. Also, in terms of the residual tendency, clear interhemispheric differences are visible in particular during the winter season (panel f). While in the Southern Hemisphere the eddy transport contributes to weaken the annual cycle, it does the opposite in the Northern Hemisphere. At higher northern latitudes the behaviour of the residual tendency becomes more similar to the Southern Hemisphere. Overall, interhemispheric differences can be found in all processes, giving rise to the annual variation. In addition, there are clear interhemispheric differences in the relative importance of the processes, with the vertical advection being less important for the total budget in the Northern Hemisphere than in the Southern Hemisphere. 

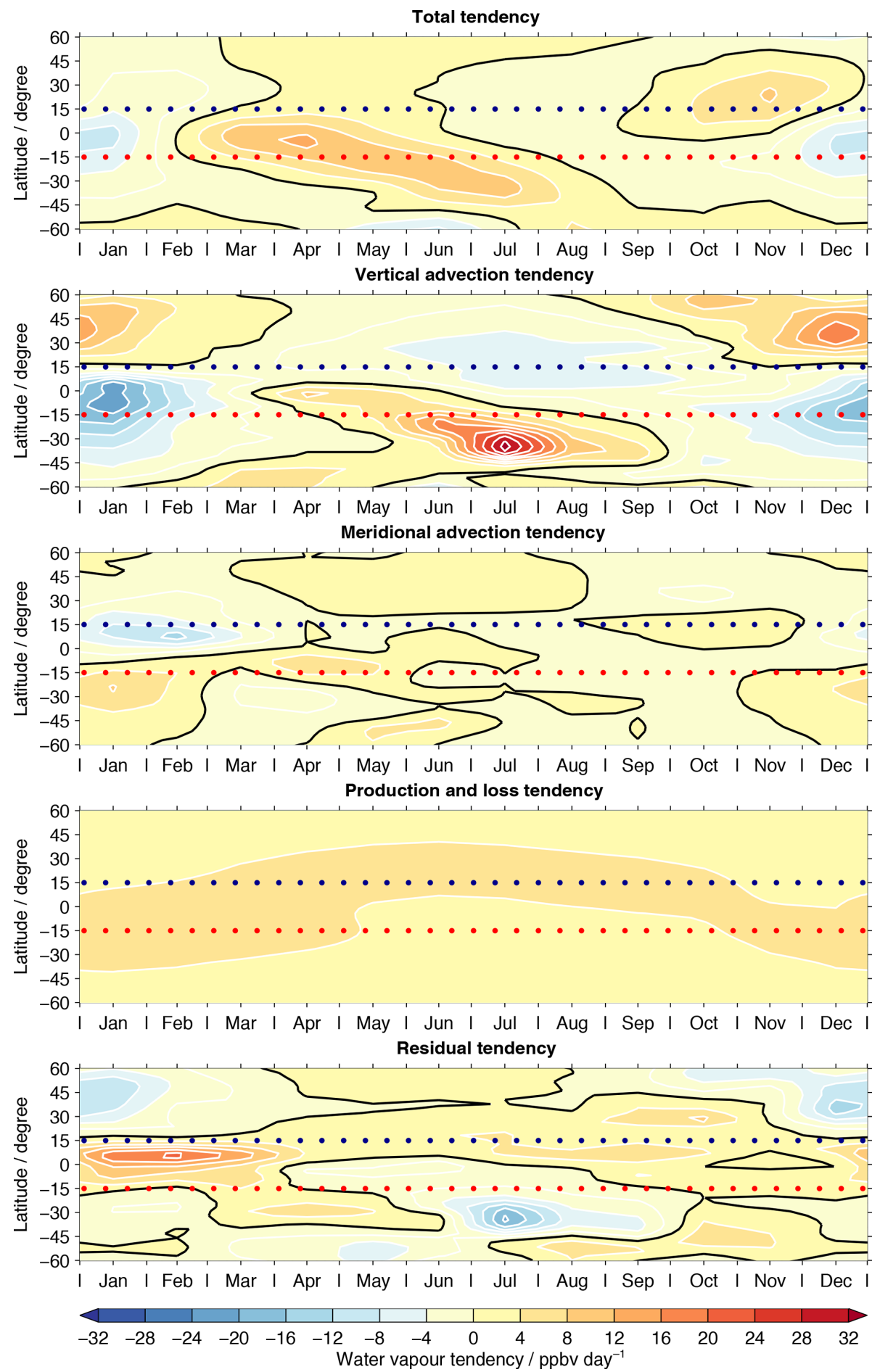

Figure 13. The latitudinal structure of the different tendencies at $3.2 \mathrm{hPa}$. The dotted lines again indicate the latitude at which the enhanced annual variation maximises (red) and the same latitude in the Northern Hemisphere (dark blue) for comparison. Note the different contours compared to Fig. 10.

\section{Conclusions}

Water vapour (and other longer-lived trace gases) exhibits an isolated maximum in its annual variation amplitude in the middle and upper stratosphere in the southern tropics and subtropics. The peak variation in water vapour is typically observed around $15^{\circ} \mathrm{S}$ and close to $3 \mathrm{hPa}(\sim 40.5 \mathrm{~km})$. Vertical advection basically explains the temporal variation, but 

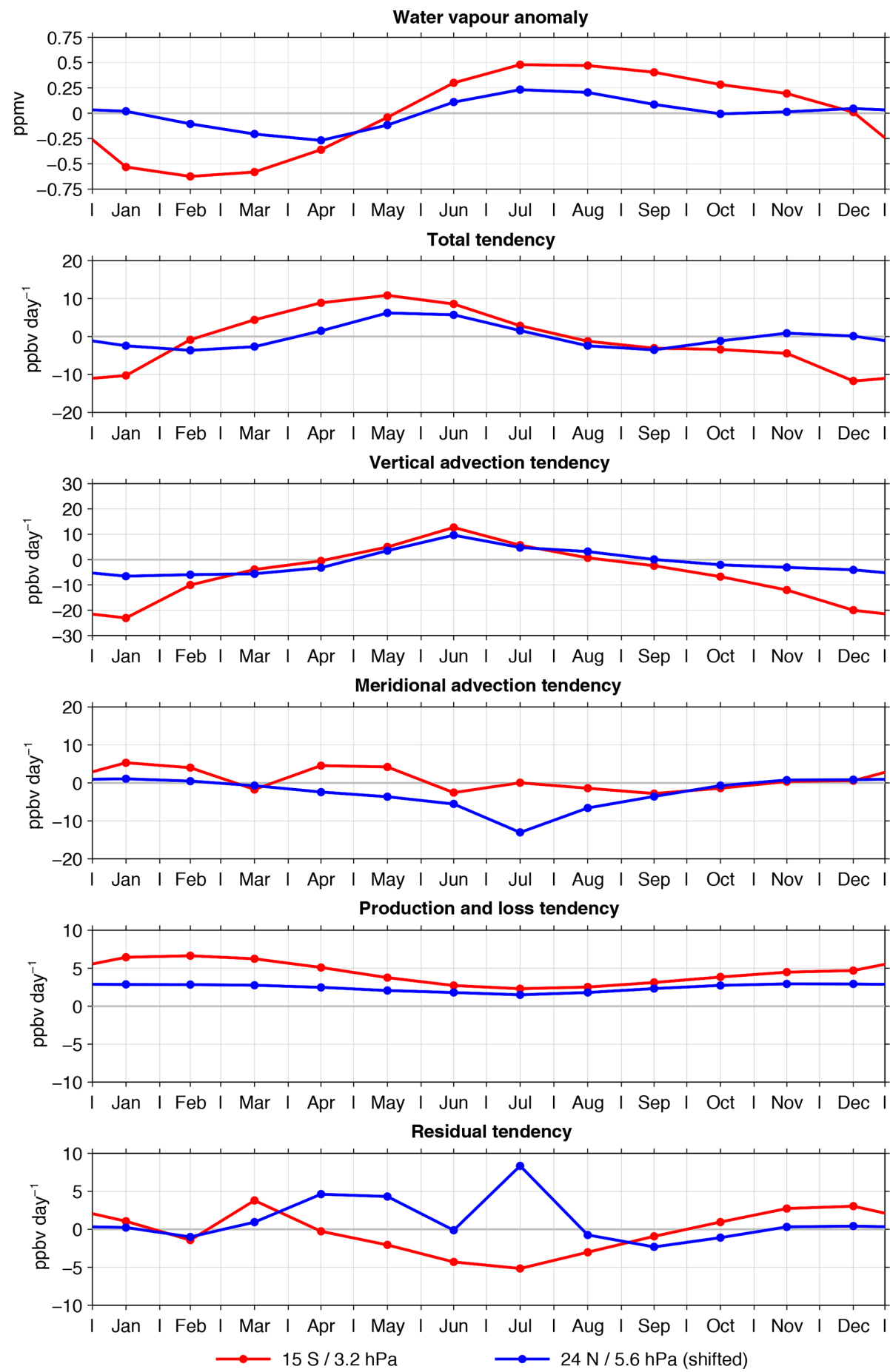

Figure 14. Comparison of the water vapour tendencies at $15^{\circ} \mathrm{S} / 3.2 \mathrm{hPa}$ and at $24^{\circ} \mathrm{N} / 5.6 \mathrm{hPa}$. The results for the Northern Hemisphere have been shifted by 6 months to allow a better visual comparison.

meridional advection and eddy transports are also needed to explain the feature and its structure. Chemistry contributes as well but is of secondary importance. It just causes smaller adjustments, for example in the exact amplitude of the variation. There is also a northern hemispheric counterpart of this feature, although it is weaker in amplitude and more shifted towards higher latitudes and lower altitudes. Hemispheric differences in the vertical transport of the BrewerDobson circulation, which is weaker in the Southern than the Northern Hemisphere, contribute to this interhemispheric asymmetry in the annual variation of water vapour. As the ascent occurs in the opposite hemisphere, there is stronger up- 


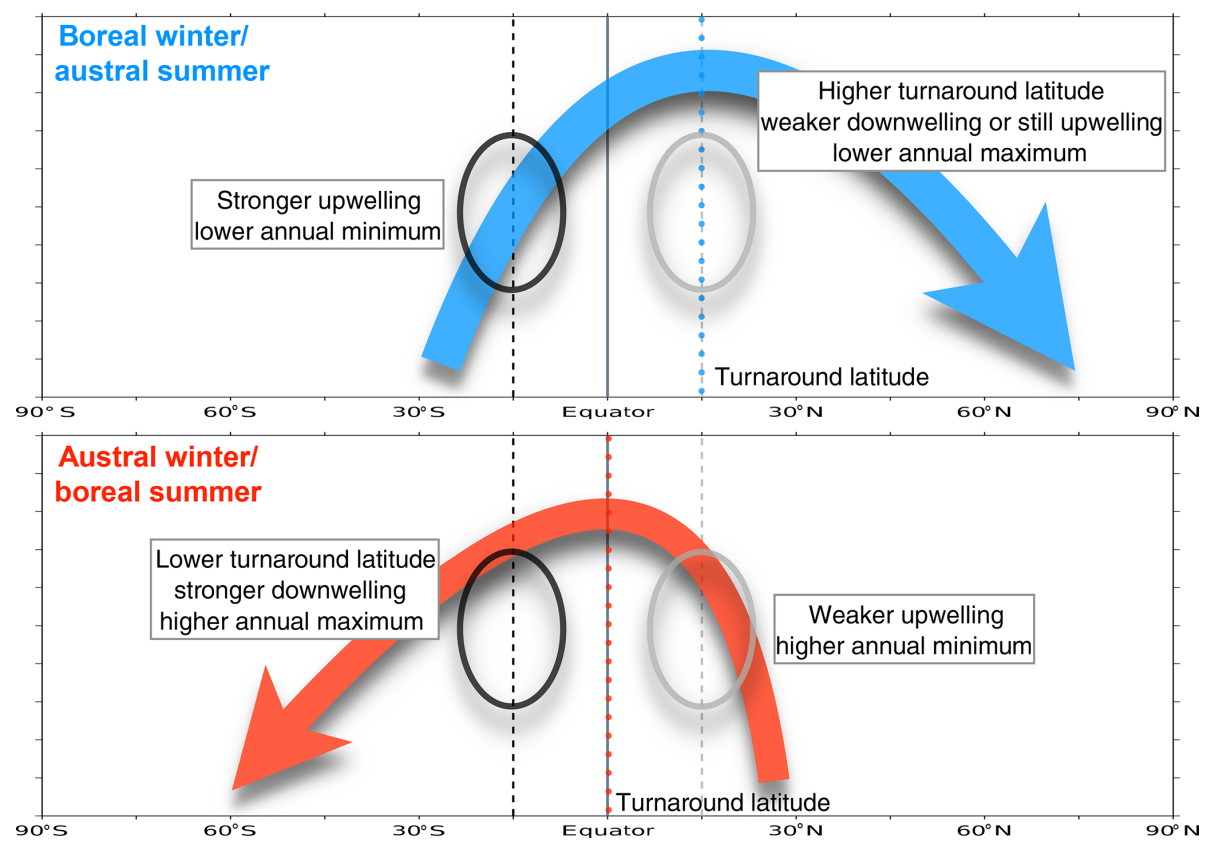

Figure 15. A summary sketch of the main aspects of the enhanced annual variation with respect to the vertical advection of the BrewerDobson circulation. Panel (a) shows the situation during boreal winter (austral summer), while (b) focuses on austral winter (boreal summer). The region of the enhanced annual variation is depicted by the black oval. The corresponding latitude region in the Northern Hemisphere is given in grey. The turnaround latitudes, i.e. the latitudes where the transition from upwelling to downwelling occurs, are indicated by coloured dotted lines.

welling in boreal winter in the Southern Hemisphere, which leads to lower water vapour volume mixing ratios than in the Northern Hemisphere in austral winter. The weaker circulation towards the south in austral winter leads to a transition from upwelling to downwelling in the middle and upper stratosphere around the Equator. For the stronger circulation towards the north this transition first occurs around $15^{\circ} \mathrm{N}$. This explains larger volume mixing ratios during winter in the Southern Hemisphere compared to the north. In addition, it also explains the different latitude band in which the northern counterpart occurs. Also, differences in other processes contribute to the interhemispheric differences. The relative importance of the individual process for these differences clearly varies in time and space, occasionally outweighing the vertical advection. As a summary, Fig. 15 sketches the main aspects of the enhanced annual variation and the differences with the corresponding latitude in the Northern Hemisphere with respect to the vertical advection within the Brewer-Dobson circulation.

The enhanced annual variation and its northern hemispheric counterpart inevitably present themselves as a natural evaluation parameter for model simulations. As the tape recorder signal in water vapour is used to assess the quality of simulations with respect to the ascent of the Brewer-Dobson circulation in the tropical lower stratosphere, the enhanced annual variation can serve as a benchmark for the quality of simulations with regard to this circulation in the middle and upper stratosphere. Given the occurrence of this feature in multiple trace gases with slightly different characteristics based on different chemistry and gradients, the assessment will be more rigorous than for other evaluation parameters. We have looked into the results from a number of model simulations, both those that use specified dynamics and those that are free running (not shown here). They exhibit distinct differences in the characteristics of the enhanced annual variation and its northern hemispheric counterpart, clearly warranting further analyses. For EMAC the application of specified dynamics up to $1 \mathrm{hPa}$ (see Introduction) yields a much better agreement with the observations than the standard application up to only $10 \mathrm{hPa}$. This hints towards some deficits in the wave driving of the Brewer-Dobson circulation in the model. It also seems to highlight the quality of the ERAInterim reanalysis data in the upper stratosphere.

Data availability. The data sets used in this work can be accessed as follows:

- The MIPAS data are available on the following website: https: //www.imk-asf.kit.edu/english/308.php ${ }^{1}$.

- The SMR data can be accessed on the following website: http: //amazonite.rss.chalmers.se:8280/OdinSMR/searchl2 ${ }^{2}$.

\footnotetext{
${ }^{1}$ registration needed

${ }^{2}$ registration needed
} 
- The data of the EMAC simulations described above will be made available in the Climate and Environmental Retrieval and Archive (CERA) database at the German Climate Computing Centre (DKRZ, website: http://cera-www.dkrz.de/WDCC/ui/ Index.jsp). The corresponding digital object identifiers (DOI) will be published on the MESSy consortium website (http: //www.messy-interface.org). Alternatively, the data can be obtained on request from Patrick Jöckel (patrick.joeckel@dlr.de).

Competing interests. The authors declare that they have no conflict of interest.

Special issue statement. This article is part of the special issue "Water vapour in the upper troposphere and middle atmosphere: a WCRP/SPARC satellite data quality assessment including biases, variability, and drifts (ACP/AMT/ESSD inter-journal SI)". It is not associated with a conference.

Acknowledgements. Stefan Lossow was funded by the DFG Research Unit "Stratospheric Change and its Role for Climate Prediction" (SHARP) under contract STI 210/9-2. Hella Garny was funded by the Helmholtz Association under grant VH-NG-1014 (Helmholtz Hochschu-Nachwuchsforschergruppe MACClim). We would like to thank the European Space Agency (ESA) for making the MIPAS level-1b data set available. Odin is a Swedish-led satellite project funded jointly by the Swedish National Space Board (SNSB), the Canadian Space Agency (CSA), the National Technology Agency of Finland (Tekes) and the Centre National d'Etudes Spatiales (CNES) in France. The Swedish Space Corporation has been the industrial prime constructor. Since April 2007 Odin is a third-party mission of ESA. The EMAC simulations have been performed at the German Climate Computing Centre (DKRZ) through support from the Bundesministerium für Bildung und Forschung (BMBF). DKRZ and its scientific steering committee are gratefully acknowledged for providing the high performance computing (HPC) and data archiving resources for ESCiMo (Earth System Chemistry integrated Modelling) consortial project. We thank Gerald E. Nedoluha from the Naval Research Laboratory and three anonymous reviewers for valuable comments. Rest in peace Chester Bennington: sometimes goodbye is the only way.

We acknowledge support by Deutsche Forschungsgemeinschaft and Open Access Publishing Fund of Karlsruhe Institute of Technology.

The article processing charges for this open-access publication were covered by a Research

Centre of the Helmholtz Association.

Edited by: Karen Rosenlof

Reviewed by: three anonymous referees

\section{References}

Abalos, M., Randel, W. J., Kinnison, D. E., and Serrano, E.: Quantifying tracer transport in the tropical lower stratosphere using WACCM, Atmos. Chem. Phys., 13, 10591-10607, https://doi.org/10.5194/acp-13-10591-2013, 2013.

Brasseur, G. and Solomon, S.: Aeronomy of the middle atmosphere, Springer, ISBN-10 1-4020-3284-6, P.O. Box 17, 3300 AA Dordrecht, The Netherlands, 2005.

Brinkop, S., Dameris, M., Jöckel, P., Garny, H., Lossow, S., and Stiller, G.: The millennium water vapour drop in chemistryclimate model simulations, Atmos. Chem. Phys., 16, 8125-8140, https://doi.org/10.5194/acp-16-8125-2016, 2016.

Carr, E. S., Harwood, R. S., Mote, P. W., Peckham, G. E., Suttie, R. A., Lahoz, W. A., O'Neill, A., Froidevaux, L., Jarnot, R. F., Read, W. G., Waters, J. W., and Swinbank, R.: Tropical stratospheric water vapor measured by the Microwave Limb Sounder (MLS), Geophys. Res. Lett., 22, 691694, https://doi.org/10.1029/95GL00626, 1995.

Chirkov, M., Stiller, G. P., Laeng, A., Kellmann, S., von Clarmann, T., Boone, C. D., Elkins, J. W., Engel, A., Glatthor, N., Grabowski, U., Harth, C. M., Kiefer, M., Kolonjari, F., Krummel, P. B., Linden, A., Lunder, C. R., Miller, B. R., Montzka, S. A., Mühle, J., O’Doherty, S., Orphal, J., Prinn, R. G., Toon, G., Vollmer, M. K., Walker, K. A., Weiss, R. F., Wiegele, A., and Young, D.: Global HCFC-22 measurements with MIPAS: retrieval, validation, global distribution and its evolution over 2005-2012, Atmos. Chem. Phys., 16, 3345-3368, https://doi.org/10.5194/acp-16-3345-2016, 2016.

Dee, D. P., Uppala, S. M., Simmons, A. J., Berrisford, P., Poli, P., Kobayashi, S., Andrae, U., Balmaseda, M. A., Balsamo, G., Bauer, P., Bechtold, P., Beljaars, A. C. M., van de Berg, L., Bidlot, J., Bormann, N., Delsol, C., Dragani, R., Fuentes, M., Geer, A. J., Haimberger, L., Healy, S. B., Hersbach, H., Hólm, E. V., Isaksen, L., Kållberg, P., Köhler, M., Matricardi, M., McNally, A. P., Monge-Sanz, B. M., Morcrette, J.-J., Park, B.-K., Peubey, C., de Rosnay, P., Tavolato, C., Thépaut, J.-N., and Vitart, F.: The ERA-Interim reanalysis: configuration and performance of the data assimilation system, Q. J. Roy. Meteor. Soc., 137, 553-597, https://doi.org/10.1002/qj.828, 2011.

Dessler, A. E., Schoeberl, M. R., Wang, T., Davis, S. M., and Rosenlof, K. H.: Stratospheric water vapor feedback, Proceedings of the National Academy of Science, 110, 18087-18091, https://doi.org/10.1073/pnas.1310344110, 2013.

Dessler, A. E., Schoeberl, M. R., Wang, T., Davis, S. M., Rosenlof, K. H., and Vernier, J.-P.: Variations of stratospheric water vapor over the past three decades, J. Geophys. Res., 119, 12588-12598, https://doi.org/10.1002/2014JD021712, 2014.

Dessler, A. E., Ye, H., Wang, T., Schoeberl, M. R., Oman, L. D., Douglass, A. R., Butler, A. H., Rosenlof, K. H., Davis, S. M., and Portmann, R. W.: Transport of ice into the stratosphere and the humidification of the stratosphere over the 21st century, Geophys. Res. Lett., 43, 2323-2329, https://doi.org/10.1002/2016GL067991, 2016.

Dietmüller, S., Garny, H., Plöger, F., Jöckel, P., and Cai, D.: Effects of mixing on resolved and unresolved scales on stratospheric age of air, Atmos. Chem. Phys., 17, 7703-7719, https://doi.org/10.5194/acp-17-7703-2017, 2017.

Eckert, E., Laeng, A., Lossow, S., Kellmann, S., Stiller, G., von Clarmann, T., Glatthor, N., Höpfner, M., Kiefer, M., Oelhaf, H., 
Orphal, J., Funke, B., Grabowski, U., Haenel, F., Linden, A., Wetzel, G., Woiwode, W., Bernath, P. F., Boone, C., Dutton, G. S., Elkins, J. W., Engel, A., Gille, J. C., Kolonjari, F., Sugita, T., Toon, G. C., and Walker, K. A.: MIPAS IMK/IAA CFC-11 $\left(\mathrm{CCl}_{3} \mathrm{~F}\right)$ and $\mathrm{CFC}-12\left(\mathrm{CCl}_{2} \mathrm{~F}_{2}\right)$ measurements: accuracy, precision and long-term stability, Atmos. Meas. Tech., 9, 3355-3389, https://doi.org/10.5194/amt-9-3355-2016, 2016.

Eichinger, R., Jöckel, P., and Lossow, S.: Simulation of the isotopic composition of stratospheric water vapour - Part 2: Investigation of $\mathrm{HDO} / \mathrm{H}_{2} \mathrm{O}$ variations, Atmos. Chem. Phys., 15, 7003-7015, https://doi.org/10.5194/acp-15-7003-2015, 2015.

Eyring, V., Lamarque, J.-F., Hess, P., Arfeuille, F., Bowman, K., Chipperfield, M. P., Duncan, B., Fiore, A., Gettelman, A., Giorgetta, M. A., Granier, C., Hegglin, M. I., Kinnison, D., Kunze, M., Langematz, U., Luo, B., Martin, R., Matthes, K., Newman, P. A., Peter, T., Robock, A., Ryerson, T., Saiz-Lopez, A., Salawitch, R., Schultz, M., Shepherd, T. G., Shindell, D., Staehelin, J., Tegtmeier, S., Thomason, L., Tilmes, S., Vernier, J.P., Waugh, D. W., and Young, P. J.: Overview of IGAC/SPARC Chemistry-Climate Model Initiative (CCMI) community simulations in support of upcoming ozone and climate assessments, SPARC Newsletter, 40, 48-66, 2013.

Fischer, H., Birk, M., Blom, C., Carli, B., Carlotti, M., von Clarmann, T., Delbouille, L., Dudhia, A., Ehhalt, D., Endemann, M., Flaud, J. M., Gessner, R., Kleinert, A., Koopman, R., Langen, J., López-Puertas, M., Mosner, P., Nett, H., Oelhaf, H., Perron, G., Remedios, J., Ridolfi, M., Stiller, G., and Zander, R.: MIPAS: an instrument for atmospheric and climate research, Atmos. Chem. Phys., 8, 2151-2188, https://doi.org/10.5194/acp-8-21512008, 2008.

Hegglin, M. I., Plummer, D. A., Shepherd, T. G., Scinocca, J. F., Anderson, J., Froidevaux, L., Funke, B., Hurst, D., Rozanov, A., Urban, J., von Clarmann, T., Walker, K. A., Wang, H. J., Tegtmeier, S., and Weigel, K.: Vertical structure of stratospheric water vapour trends derived from merged satellite data, Nat. Geosci., 7, 768-776, https://doi.org/10.1038/ngeo2236, 2014.

Holton, J. R. and Choi, W.-K.: Transport circulation deduced from SAMS trace species data, J. Atmos. Sci., 45, 1929-1939, https://doi.org/10.1175/15200469(1988)045<1929:TCDFST>2.0.CO;2, 1988.

Hurst, D. F., Oltmans, S. J., Vömel, H., Rosenlof, K. H., Davis, S. M., Ray, E. A., Hall, E. G., and Jordan, A. F.: Stratospheric water vapor trends over Boulder, Colorado: Analysis of the 30 year Boulder record, J. Geophys. Res., 116, D02306, https://doi.org/10.1029/2010JD015065, 2011.

Jackson, D. R., Burrage, M. D., Harries, J. E., Gray, L. J., and Russell, J. M.: The semi-annual oscillation in upper stratospheric and mesospheric water vapour as observed by HALOE, Q. J. Roy. Meteor. Soc., 124, 2493-2515, https://doi.org/10.1256/smsqj.55115, 1998.

Jöckel, P., Tost, H., Pozzer, A., Kunze, M., Kirner, O., Brenninkmeijer, C. A. M., Brinkop, S., Cai, D. S., Dyroff, C., Eckstein, J., Frank, F., Garny, H., Gottschaldt, K.-D., Graf, P., Grewe, V., Kerkweg, A., Kern, B., Matthes, S., Mertens, M., Meul, S., Neumaier, M., Nützel, M., Oberländer-Hayn, S., Ruhnke, R., Runde, T., Sander, R., Scharffe, D., and Zahn, A.: Earth System Chemistry integrated Modelling (ESCiMo) with the Modular Earth Submodel System (MESSy) version 2.51, Geosci. Model Dev., 9, 1153-1200, https://doi.org/10.5194/gmd-9-1153-2016, 2016.
Le Texier, H., Solomon, S., and Garcia, R. R.: The role of molecular hydrogen and methane oxidation in the water vapour budget of the stratosphere, Q. J. Roy. Meteor. Soc., 114, 281-295, https://doi.org/10.1002/qj.49711448002, 1988.

Löffler, M., Brinkop, S., and Jöckel, P.: Impact of major volcanic eruptions on stratospheric water vapour, Atmos. Chem. Phys., 16, 6547-6562, https://doi.org/10.5194/acp-166547-2016, 2016.

Lossow, S., Urban, J., Gumbel, J., Eriksson, P., and Murtagh, D.: Observations of the mesospheric semi-annual oscillation (MSAO) in water vapour by Odin/SMR, Atmos. Chem. Phys., 8, 6527-6540, https://doi.org/10.5194/acp-8-6527-2008, 2008.

Lossow, S., Khosrawi, F., Nedoluha, G. E., Azam, F., Bramstedt, K., Burrows, John. P., Dinelli, B. M., Eriksson, P., Espy, P. J., GarcíaComas, M., Gille, J. C., Kiefer, M., Noël, S., Raspollini, P., Read, W. G., Rosenlof, K. H., Rozanov, A., Sioris, C. E., Stiller, G. P., Walker, K. A., and Weigel, K.: The SPARC water vapour assessment II: comparison of annual, semi-annual and quasi-biennial variations in stratospheric and lower mesospheric water vapour observed from satellites, Atmos. Meas. Tech., 10, 1111-1137, https://doi.org/10.5194/amt-10-1111-2017, 2017.

Mote, P. W., Rosenlof, K. H., McIntyre, M. E., Carr, E. S., Gille, J. C., Holton, J. R., Kinnersley, J. S., Pumphrey, H. C., Russell, J. M., and Waters, J. W.: An atmospheric tape recorder: The imprint of tropical tropopause temperatures on stratospheric water vapor, J. Geophys. Res., 101, 3989-4006, https://doi.org/10.1029/95JD03422, 1996.

Murtagh, D. P., Frisk, U., Merino, F., Ridal, M., Jonsson, A., Stegman, J., Witt, G., Eriksson, P., Jiménez, C., Megie, G., de La Noë, J., Ricaud, P., Baron, P., Pardo, J. R., Hauchcorne, A., Llewellyn, E. J., Degenstein, D. A., Gattinger, R. L., Lloyd, N. D., Evans, W. F. J., McDade, I. C., Haley, C. S., Sioris, C., von Savigny, C., Solheim, B. H., McConnell, J. C., Strong, K., Richardson, E. H., Leppelmeier, G. W., Kyrölä, E., Auvinen, H., and Oikarinen, L.: An overview of the Odin atmospheric mission, Can. J. Phys., 80, 309-319, https://doi.org/10.1139/p01$157,2002$.

Oltmans, S. J., Vömel, H., Hofmann, D. J., Rosenlof, K. H., and Kley, D.: The increase in stratospheric water vapor from balloonborne, frostpoint hygrometer measurements at Washington, D.C., and Boulder, Colorado, Geophys. Res. Lett., 27, 34533456, https://doi.org/10.1029/2000GL012133, 2000.

Plieninger, J., Laeng, A., Lossow, S., von Clarmann, T., Stiller, G. P., Kellmann, S., Linden, A., Kiefer, M., Walker, K. A., Noël, S., Hervig, M. E., McHugh, M., Lambert, A., Urban, J., Elkins, J. W., and Murtagh, D.: Validation of revised methane and nitrous oxide profiles from MIPAS-ENVISAT, Atmos. Meas. Tech., 9, 765-779, https://doi.org/10.5194/amt-9-765-2016, 2016.

Ploeger, F., Günther, G., Konopka, P., Fueglistaler, S., Müller, R., Hoppe, C., Kunz, A., Spang, R., Grooß, J.-U., and Riese, M.: Horizontal water vapor transport in the lower stratosphere from subtropics to high latitudes during boreal summer, J. Geophys. Res., 118, 8111-8127, https://doi.org/10.1002/jgrd.50636, 2013.

Randel, W. J., Wu, F., Russell, J. M., Roche, A., and Waters, J. W.: Seasonal cycles and QBO variations in stratospheric $\mathrm{CH}_{4}$ and $\mathrm{H}_{2} \mathrm{O}$ observed in UARS HALOE data, J. Atmos. Sci., 55, 163-185, https://doi.org/10.1175/15200469(1998)055<0163:SCAQVI>2.0.CO;2, 1998. 
Randel, W. J., Wu, F., Vömel, H., Nedoluha, G. E., and Forster, P.: Decreases in stratospheric water vapor after 2001: Links to changes in the tropical tropopause and the Brewer-Dobson circulation, J. Geophys. Res., 111, D12312, https://doi.org/10.1029/2005JD006744, 2006.

Riese, M., Ploeger, F., Rap, A., Vogel, B., Konopka, P., Dameris, M., and Forster, P.: Impact of uncertainties in atmospheric mixing on simulated UTLS composition and related radiative effects, J. Geophys. Res., 117, D16305, https://doi.org/10.1029/2012JD017751, 2012.

Rosenlof, K. H.: Seasonal cycle of the residual mean meridional circulation in the stratosphere, J. Geophys. Res., 100, 5173-5191, https://doi.org/10.1029/94JD03122, 1995.

Rosenlof, K. H., Chiou, E.-W., Chu, W. P., Johnson, D. G., Kelly, K. K., Michelsen, H. A., Nedoluha, G. E., Remsberg, E. E., Toon, G. C., and McCormick, M. P.: Stratospheric water vapor increases over the past half-century, Geophys. Res. Lett., 28, 1195-1198, https://doi.org/10.1029/2000GL012502, 2001.

Schieferdecker, T., Lossow, S., Stiller, G. P., and von Clarmann, T.: Is there a solar signal in lower stratospheric water vapour?, Atmos. Chem. Phys., 15, 9851-9863, https://doi.org/10.5194/acp15-9851-2015, 2015.

Siskind, D. E. and Summers, M. E.: Implications of enhanced mesospheric water vapor observed by HALOE, Geophys. Res. Lett., 25, 2133-2136, https://doi.org/10.1029/98GL51608, 1998.
Siskind, D. E., Eckermann, S. D., McCormack, J. P., Alexander, M. J., and Bacmeister, J. T.: Hemispheric differences in the temperature of the summertime stratosphere and mesosphere, J. Geophys. Res., 108, 4051, https://doi.org/10.1029/2002JD002095, 2003.

Smith, A. K.: Global Dynamics of the MLT, Surv. Geophys., 33 1177-1230, https://doi.org/10.1007/s10712-012-9196-9, 2012.

Tao, M., Konopka, P., Ploeger, F., Riese, M., Müller, R., and Volk, C. M.: Impact of stratospheric major warmings and the quasi-biennial oscillation on the variability of stratospheric water vapor, Geophys. Res. Lett., 42, 4599-4607, https://doi.org/10.1002/2015GL064443, 2015.

Urban, J., Lossow, S., Stiller, G., and Read, W.: Another drop in water vapor, EOS Transactions, 95, 245-246, https://doi.org/10.1002/2014EO270001, 2014.

von Clarmann, T., Höpfner, M., Kellmann, S., Linden, A., Chauhan, S., Funke, B., Grabowski, U., Glatthor, N., Kiefer, M., Schieferdecker, T., Stiller, G. P., and Versick, S.: Retrieval of temperature, $\mathrm{H}_{2} \mathrm{O}, \mathrm{O}_{3}, \mathrm{HNO}_{3}, \mathrm{CH}_{4}, \mathrm{~N}_{2} \mathrm{O}, \mathrm{ClONO}_{2}$ and $\mathrm{ClO}$ from MIPAS reduced resolution nominal mode limb emission measurements, Atmos. Meas. Tech., 2, 159-175, https://doi.org/10.5194/amt-2159-2009, 2009. 